\title{
An Atom Probe Study of Kappa Carbide Precipitation and the Effect of Silicon Addition
}

\author{
LAURA N. BARTLETT, DAVID C. VAN AKEN, JULIA MEDVEDEVA, \\ DIETER ISHEIM, NADEZHDA I. MEDVEDEVA, and KAI SONG
}

\begin{abstract}
The influence of silicon on $\kappa$-carbide precipitation in lightweight austenitic Fe-30Mn-9Al-(0.591.56)Si-0.9C-0.5Mo cast steels was investigated utilizing transmission electron microscopy, $3 \mathrm{D}$ atom-probe tomography, X-ray diffraction, ab initio calculations, and thermodynamic modeling. Increasing the amount of silicon from 0.59 to $1.56 \mathrm{pct} \mathrm{Si}$ accelerated formation of the $\kappa$-carbide precipitates but did not increase the volume fraction. Silicon was shown to increase the activity of carbon in austenite and stabilize the $\kappa$-carbide at higher temperatures. Increasing the silicon from 0.59 to $1.56 \mathrm{pct}$ increased the partitioning coefficient of carbon from 2.1 to 2.9 for steels aged 60 hours at $803 \mathrm{~K}\left(530^{\circ} \mathrm{C}\right)$. The increase in strength during aging of Fe-Mn-Al-C steels was found to be a direct function of the increase in the concentration amplitude of carbon during spinodal decomposition. The predicted increase in the yield strength, as determined using a spinodal hardening mechanism, was calculated to be $120 \mathrm{MPa} / \mathrm{wt}$ pct Si for specimens aged at $803 \mathrm{~K}\left(530^{\circ} \mathrm{C}\right)$ for 60 hours and this is in agreement with experimental results. Silicon was shown to partition to the austenite during aging and to slightly reduce the austenite lattice parameter. First-principles calculations show that the Si-C interaction is repulsive and this is the reason for enhanced carbon activity in austenite. The lattice parameter and thermodynamic stability of $\kappa$-carbide depend on the carbon stoichiometry and on which sublattice the silicon substitutes. Silicon was shown to favor vacancy ordering in $\kappa$-carbide due to a strong attractive $\mathrm{Si}$-vacancy interaction. It was predicted that $\mathrm{Si}$ occupies the $\mathrm{Fe}$ sites in nonstoichiometric $\kappa$-carbide and the formation of Si-vacancy complexes increases the stability as well as the lattice parameter of $\kappa$-carbide. A comparison of how Si affects the enthalpy of formation for austenite and $\kappa$-carbide shows that the most energetically favorable position for silicon is in austenite, in agreement with the experimentally measured partitioning ratios.
\end{abstract}

DOI: $10.1007 / \mathrm{s} 11661-014-2187-3$

(C) The Minerals, Metals \& Materials Society and ASM International 2014

\section{INTRODUCTION}

CAST lightweight austenitic Fe-Mn-Al-C steels have both low melting points, less than $(1623 \mathrm{~K}) 1350{ }^{\circ} \mathrm{C}$, and good filling characteristics which are similar to cast irons. ${ }^{[1]}$ Addition of 9 to $10 \mathrm{wt}$ pct aluminum reduces the density by up to 15 pct when compared with traditional steels and may be of interest to the transportation industry as corporate average fuel economy is increased to $54.5 \mathrm{mpg}$ by 2025 . These high aluminum

LAURA N. BARTLETT, Assistant Professor, is with the Texas State University Department of Engineering Technology, San Marcos TX. Contact e-mail: lnb29@txstate.edu DAVID C. VAN AKEN, Curator's Teaching Professor, is with the Metallurgical Engineering, Missouri University of Science and Technology, Rolla MO. JULIA MEDVEDEVA, Associate Professor, is with the Physics Department, Missouri University of Science and Technology, Rolla MO. DIETER ISHEIM, Research Assistant Professor, is with the Northwestern University Center for Atom Probe Tomography, Evanston IL. NADEZHDA I. MEDVEDEVA, Senior Research Scientist, is with the Institute of Solid State Chemistry, Ural Branch of the Russian Academy of Science, Ekaterinburg, Russia. KAI SONG, formerly Senior Research Specialist with the Missouri University of Science and Technology, is now Senior Applications Engineer with the FEI Company, Hillsboro, OR.

Manuscript submitted June 7, 2013.

Article published online February 20, 2014 steels can be competitive in terms of strength with quenched and tempered steels when age hardened. However, the high manganese (20 to $30 \mathrm{wt}$ pct) required to stabilize an austenitic matrix ${ }^{[1,2]}$ may relegate this class of steel to castings, since electrolytic manganese is required to limit phosphorus and may be too costly for current steelmaking practices. ${ }^{[3]}$ Grades that contain from 5 to $11 \mathrm{wt}$ pet aluminum and from 0.3 to $1.2 \mathrm{wt}$ pet carbon are age hardenable when heat treated in the range of $723 \mathrm{~K}$ to $973 \mathrm{~K}\left(450{ }^{\circ} \mathrm{C}\right.$ to $\left.700{ }^{\circ} \mathrm{C}\right) \cdot{ }^{[2-4]}$ All compositions in the following text are in weight percent unless otherwise stated. Depending on the heat treatment, cast alloys can attain strengths as high as $1100 \mathrm{MPa}$ in the age-hardened condition and good ductility in the solution-treated condition with total elongations greater than 64 pct. $^{[3,5]}$ Excellent strengths and high work hardening rates with up to a 15 pct reduction in density make these alloys very attractive for high energy absorbing applications. ${ }^{[2]}$ However, the mechanical properties are a function of age hardening and knowledge of how alloying additions and impurities affect aging is of primary interest when qualifying these steels for high energy absorbing or low temperature applications.

Hardening is attained by the homogeneous and coherent precipitation of nano-sized $\kappa$-carbide, $(\mathrm{Fe}, \mathrm{Mn})_{3} \mathrm{AlC}_{x}$. $\kappa$-carbide has the $\mathrm{E} 2{ }_{1}$ cubic perovskite crystal structure in 
which aluminum occupies corner positions, iron and manganese occupy face-centered positions, and carbon is at the body center interstitial octahedral site. $\kappa$-carbide has a cube on cube orientation relationship with the austenitic matrix with $\langle 100\rangle_{\kappa} / /\langle 100\rangle_{\gamma}$ and $\{001\}_{\kappa} / /$ $\{001\} \gamma^{[6-10]}$ Studies indicate that first stage hardening in $\mathrm{Fe}-\mathrm{Mn}$ - $\mathrm{Al}-\mathrm{C}$ alloys is the result of compositional modulation produced by spinodal decomposition into either carbon rich $^{[10-13]}$ or carbon and aluminum rich $^{[6,8,9,14]}$ and depleted zones. Spinodal decomposition is thought to either precede, ${ }^{[9]}$ take place concurrently to ${ }^{[6,10,12-15]}$ or subsequently ${ }^{[8,11]}$ to short-range ordering into lattice sites corresponding to the $\kappa$-carbide structure. This is followed by coarsening with the development of cuboidal-shaped precipitates periodically arranged along $\langle 100\rangle$.

Silicon is one of the most common alloying additions to high manganese and aluminum steels. Silicon increases the fluidity and decreases the melting point by $303 \mathrm{~K}\left(30^{\circ} \mathrm{C}\right) /$ wt pet $\mathrm{Si}^{\left[{ }^{[1]}\right.}$ Most importantly, adding silicon has been reported to prevent or severely retard the precipitation of brittle $\beta$ - Mn, which is deleterious to impact toughness in age-hardened materials. ${ }^{[8]}$ Increasing the amount of silicon from 1.0 to $1.56 \mathrm{pct}$ in an alloy of nominal composition Fe-30Mn-9A1-0.9C-0.5Mo increases the strength and hardness during aging but decreases the work hardening rate and the total elongation to failure by as much as 10 pct. ${ }^{[5,16]}$ Agehardening curves for Fe-30Mn-9Al-0.9C-0.5Mo, low phosphorus alloys $(<0.003$ pct $\mathrm{P})$ with different silicon contents are given in Figure 1(a) for specimens aged at $803 \mathrm{~K}\left(530^{\circ} \mathrm{C}\right)$. It is shown that increasing the amount of silicon appears to accelerate the onset of hardening but appears not to increase the overall hardening rate. ${ }^{[16]}$

The mechanism by which silicon accelerates hardening and prevents $\beta$-Mn in these steels is unknown. Acselrad et al. reported that silicon increases the kinetics of zone formation during spinodal decomposition. ${ }^{[8]}$

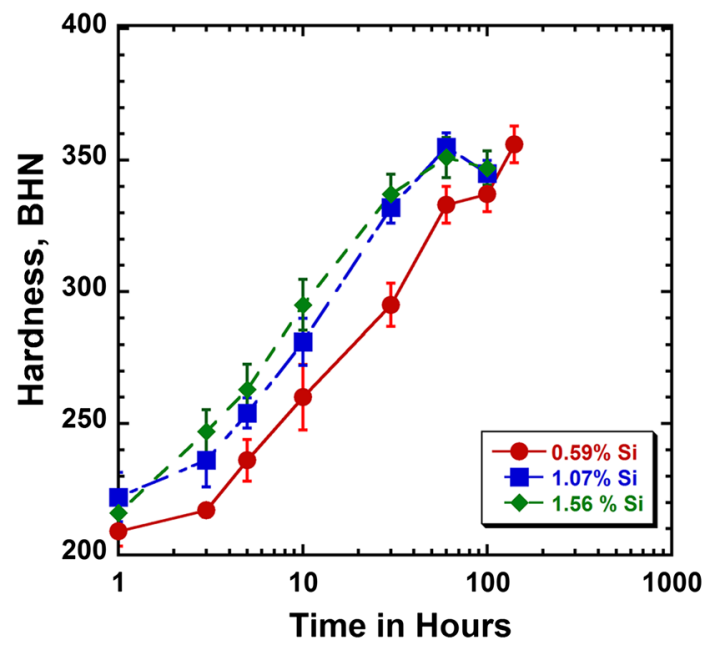

Fig. 1- Age-hardening curves for low phosphorus $(<0.003$ pct $\mathrm{P})$, Fe-30Mn-9Al-(0.59-1.56)Si-0.9C-0.5Mo steels aged at $803 \mathrm{~K}\left(530{ }^{\circ} \mathrm{C}\right)$. Silicon increases the aged hardness but appears not to increase the hardening rate.
They additionally proposed that silicon increases the partitioning of manganese from the austenite matrix into grain boundary $\kappa$-carbide precipitates during aging. ${ }^{8]}$ After sufficient aging times, the austenite was depleted of enough manganese to prevent $\beta$-Mn precipitation and $\mathrm{DO}_{3}$ or $\mathrm{B} 2$ iron aluminide phases formed instead. ${ }^{[8]}$ It is suggested that partitioning of manganese into the $\kappa$-carbide may also increase strength during aging. Manganese has a larger atomic radius, $0.179 \mathrm{~nm}$, than iron, $0.172 \mathrm{~nm}$, and therefore preferential substitution of Fe by Mn may increase the lattice parameter of the $\kappa$-carbide; thus, contributing to an increase in strength and hardness during aging. ${ }^{[16]}$

Evidence that silicon influences manganese partitioning comes from a study by Chao and Liu who reported manganese-rich grain boundary $\kappa$-carbides in a Fe-28.6Mn-9.8Al-0.8Si-1.0C steel after aging for longer than 6 hours at $873 \mathrm{~K}\left(600^{\circ} \mathrm{C}\right) .{ }^{[17]}$ The concentration of manganese in the $\kappa$-carbide was determined by energy dispersive X-ray spectroscopy (EDS) to be $46.5 \mathrm{wt}$ pct, which was almost 18 pct more manganese than the austenitic matrix composition. ${ }^{[17]}$ However, manganeserich grain boundary $\kappa$-carbides were also observed in a Fe-8Al-31.5Mn-1.05C alloy without silicon addition and $\beta$-Mn was not observed, even after extended aging for 24 hours at $823 \mathrm{~K}\left(550^{\circ} \mathrm{C}\right) .{ }^{[18]} \beta$ - Mn is reported to precipitate on grain boundaries in the temperature range of $823 \mathrm{~K}$ to $1023 \mathrm{~K}\left(550{ }^{\circ} \mathrm{C}\right.$ to $\left.750{ }^{\circ} \mathrm{C}\right)$ in alloys without silicon. ${ }^{[19]}$ In a later study by Acselrad et al., it was reported that increasing silicon to 1.4 pct shifted the kinetics for nucleation and growth of $\kappa$-carbide to shorter times and this was suggested to be the result of silicon increasing the activity of carbon in austenite, and therefore the driving force for $\kappa$-carbide formation. ${ }^{[14]}$ Acselrad et al. ${ }^{[14]}$ used EDS analysis to determine the manganese content of grain boundary $\kappa$-carbides to be 47 wt pct, which was well above the concentration of matrix manganese at $28 \mathrm{wt}$ pct. Nevertheless, in all the aforementioned studies, direct evidence of the effect of silicon on the homogeneous precipitation and composition of $\kappa$-carbide is lacking and evidence of manganese partitioning into the $\kappa$-carbide is restricted to grain boundary carbides. In addition, in all these studies, chemical analysis of the $\kappa$-carbide was performed utilizing EDS, and as such the amount of carbon could not be accurately determined. Thus, the explanation for increased hardening with silicon addition remains uncertain.

It is clear that despite 50 years of research many important questions remain as to the precipitation sequence of $\kappa$-carbide as well as the role of silicon on age hardening. Atom-probe tomography (APT) allows the accurate determination of compositions as small as $50 \mathrm{ppm}$ at interfaces with subnanometer resolution, ${ }^{[20]}$ and details of the APT method have been described in several review publications. ${ }^{[21-23]}$ Local-electrode APT, LEAP, has been used to characterize precipitation in a variety of age-hardenable alloys including stainless steels, ${ }^{[24]} \mathrm{Al}-\mathrm{Sc}$ alloys, ${ }^{[25]}$ and Ni-based superalloys. ${ }^{[23]}$ This technique has also been used to measure the extent of spinodal decomposition in Ti-Al-N thin films, ${ }^{[26]}$ $\mathrm{Fe}-\mathrm{Cr}$ binary alloys, ${ }^{[27]}$ as well as in Fe-Ni-Mn-Al 
alloys. ${ }^{[28]}$ Most recently, Seol et al. have utilized APT to study the composition of a lamellar structure of $\kappa$-carbide and ferrite in a $\mathrm{Fe}-1.2 \mathrm{C}-3.2 \mathrm{Mn}-10 \mathrm{Al}$ (in at. pct) steel. ${ }^{[29]} \kappa$-carbides were found to be manganese rich with an aluminum concentration that was close in composition to the adjoining ferrite. They suggest that manganese substitution for iron would make the $\kappa$-carbide harder and stronger because of stronger bonding between $\mathrm{Mn}-\mathrm{C}$ couples in comparison to $\mathrm{Fe}-\mathrm{C}$ pairs. Assuming a weak barrier model, Mn substitution for $\mathrm{Fe}$ in the $\kappa$-carbide may increase the modulus hardening, coherency hardening, or both during aging. The focus of the current work is to determine the role of silicon on the composition, morphology, thermodynamics, and precipitation kinetics of $\kappa$-carbide that is homogeneously precipitated in fully austenitic Fe-30Mn-9Al-0.9C-0.5Mo steel.

\section{EXPERIMENTS}

A series of alloys were cast with a nominal chemistry of Fe-30 pet Mn-9 pet Al- $X$ pet Si-0.9 pet C- 0.5 pet Mo and with silicon ranging from 0.56 to 1.56 pet. This silicon range was chosen to correspond with previously reported mechanical property data. ${ }^{[5]}$ Heats were prepared using electrolytic manganese, commercially pure aluminum ( $>99$ pct $\mathrm{Al}$ ), foundry grade ferrosilicon, and Desulco 9001 graphite ( $>99.9$ pct C). All heats were prepared in an induction furnace under argon cover. The melt was calcium treated followed by Ar-stirring before tapping and subsequently poured into horizontal plate molds that were prepared from phenolic no-bake olivine sand. The thickness of the as-cast plates measured approximately $1.5 \mathrm{~cm}$. All chemical analyses were performed by ion-coupled plasma spectrometry after sample dissolution in perchloric acid and are listed in Table I. Rectangular test coupons with nominal dimensions $1.4 \mathrm{~cm} \times 1.4 \mathrm{~cm} \times 2.0 \mathrm{~cm}$ were machined from the center of the plate. Each alloy was solution treated for 2 hours at $1323 \mathrm{~K}\left(1050{ }^{\circ} \mathrm{C}\right)$ in protective stainless steel bags. Specimens were individually water quenched into agitated room temperature water. Aging was conducted in a salt pot containing a mixture of sodium and potassium nitrate salts. The variation in temperature during aging was $\pm 5^{\circ} \mathrm{C}$.

Thin foils for transmission electron microscopy were prepared using a solution of 6 pct perchloric acid, $60 \mathrm{pct}$ methanol, and 34 pet butoxyethanol and a twin jet electropolisher operating at $-20{ }^{\circ} \mathrm{C}$ utilizing a DC current of 30 to $40 \mathrm{~mA}$. Thin foils were analyzed using a Tecnai F20 TEM operating at $200 \mathrm{kV}$. LEAP specimens were prepared by machining $0.3 \times 0.3 \times 10 \mathrm{~mm}$ rectangular blanks from the center of the solution treated and aged plates. Rectangular blanks were electropolished at room temperature in a two-step polishing procedure. Initial thinning of the specimen to $0.2 \mathrm{~mm}$ in diameter was performed at $20 \mathrm{~V}$ DC in a $10 \mathrm{pct}$ perchloric acid 90 pct acetic solution. Final polishing was accomplished utilizing a solution of 2 pet perchloric acid solution in butoxyethanol at $12 \mathrm{~V}$ DC to produce a tip radius less than $100 \mathrm{~nm}$. Polished tips were analyzed using a local-electrode atom probe tomograph (LEAP $4000 \mathrm{XSi}$ ), manufactured by Cameca, Madison, WI. Tips were held in a vacuum of $6.5 \times 10^{-11}$ Torr at a temperature of $60 \mathrm{~K}$. The tips were field-evaporated at a $0.5 \mathrm{pct}$ evaporation rate, and with $20 \mathrm{pJ}$ laser pulse energy at a $500 \mathrm{kHz}$ pulse repetition rate. Between 20 million and 500 million atoms were detected from each of the respective specimen tips. IVAS 3.6 software was utilized to reconstruct a 3D atom-by-atom representation of each specimen and for subsequent data analysis.

Specimens for X-ray diffraction experiments were produced from bulk specimens that were polished to a $6 \mu \mathrm{m}$ finish. Specimens were analyzed at room temperature utilizing a PANalytical X-PertPro diffractometer with $\mathrm{Cu}-\mathrm{k} \alpha$ radiation operating at $45 \mathrm{kV}$ with a tube current of $40 \mathrm{~mA}$. A nickel monochromator was utilized to filter out $\mathrm{Cu}-\mathrm{k} \beta$ radiation. Specimens were scanned over an angular range of 20 to $80 \mathrm{deg} 2 \theta$ at a rate of $1 / 8^{\circ} \min ^{-1}$.

\section{RESULTS}

In the following text, the different alloys will be referred to by their silicon contents in weight percent as listed in Table I. It should be noted that compositions obtained by LEAP are in atomic percent. Thus, for ease of comparison, steel compositions are also given in atomic percent in Table I.

\section{A. Transmission Electron Microscopy}

Thin foils for TEM were prepared from selected specimens to directly show the influence of silicon on the morphology, size, and distribution of $\kappa$-carbide as a function of aging time and temperature. Solution-treated

Table I. Steel Compositions in Weight and Atomic Percent

\begin{tabular}{|c|c|c|c|c|c|c|c|}
\hline $\mathrm{Si}$ & $\mathrm{C}$ & $\mathrm{Mn}$ & $\mathrm{P}$ & $\mathrm{S}$ & Mo & $\mathrm{Al}$ & $\mathrm{Cu}$ \\
\hline \multicolumn{8}{|c|}{ Compositions in weight percent } \\
\hline 0.59 & 0.95 & 30.35 & 0.002 & 0.006 & 0.54 & 8.74 & 0.01 \\
\hline 1.07 & 0.90 & 30.42 & 0.001 & 0.006 & 0.53 & 8.83 & 0.006 \\
\hline 1.56 & 0.89 & 29.97 & 0.002 & 0.007 & 0.53 & 8.81 & 0.006 \\
\hline \multicolumn{8}{|c|}{ Compositions in atomic percent } \\
\hline 1.00 & 3.88 & 26.65 & 0.003 & 0.009 & 0.28 & 15.90 & 0.008 \\
\hline 1.87 & 3.69 & 26.75 & 0.002 & 0.009 & 0.27 & 16.10 & 0.005 \\
\hline 2.72 & 3.63 & 26.26 & 0.003 & 0.011 & 0.27 & 16.00 & 0.005 \\
\hline
\end{tabular}



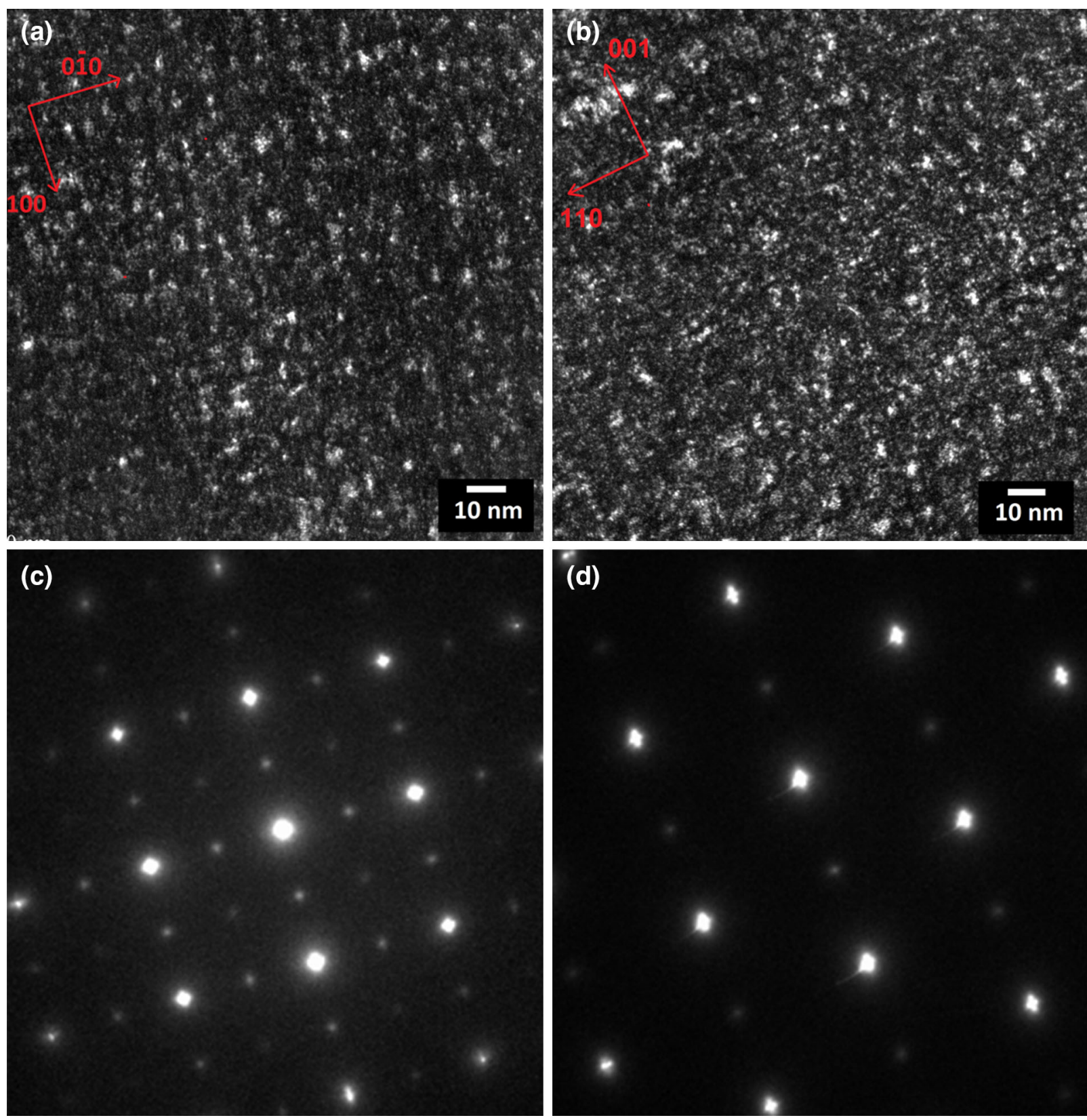

Fig. 2- (a) Dark-field images of the (a) $0.59 \mathrm{pct} \mathrm{Si}$ and (b) $1.56 \mathrm{pct} \mathrm{Si}$ steels that were aged for $63 \mathrm{~h}$ at $763 \mathrm{~K}\left(490{ }^{\circ} \mathrm{C}\right)$ show a high number density of ordered regions corresponding to the $\kappa$-carbide structure, which are on the order of 1 to $3 \mathrm{~nm}$ in diameter. The selected area diffraction patterns of the DF images in (a) and (b) corresponding to [001] and [101] zone axis, respectively, are shown in $(c)$ and $(d)$. (a) These ordered regions appear to be in the beginning stages of alignment and coarsening along a cube direction in the 0.59 pct $\mathrm{Si}$ specimen. (a and b) $\kappa$-carbide size is similar between both silicon containing specimens, however, alignment along a cube direction is difficult to claim in (b) because of the foil orientation. Both diffraction patterns show satellites flanking fundamental austenite reflections in the (c) 0.59 pct Si and (d) 1.56 pct Si specimens.

samples were single phase and there was no evidence of austenite decomposition. Electron diffraction patterns showed only fundamental austenite reflections. Figures 2(a) and (b) are dark-field images of 0.59 pct Si and 1.56 pet $\mathrm{Si}$ specimens that were aged for 63 hours at $763 \mathrm{~K}\left(490{ }^{\circ} \mathrm{C}\right)$ and both show superlattice reflections corresponding to the perovskite crystal structure of the $\kappa$-carbide. Both images were formed using a superlattice reflection associated with the $\kappa$-carbide structure and show a high number density of ordered regions that are less than $1 \mathrm{~nm}$ in diameter and are of similar size between $\mathrm{Si}$ compositions. Note that due to the projection through a finite foil thickness and the high number density of very small ordered regions, it is difficult to resolve individual precipitates. These ordered regions appear to be randomly distributed and the position of superlattice reflections shows that they have a cube on cube crystallography with the austenite matrix. High order austenite diffraction spots in the [001] SADP of the $0.59 \mathrm{pct}$ $\mathrm{Si}$ specimen in Figure 2(c) were elongated in cube 

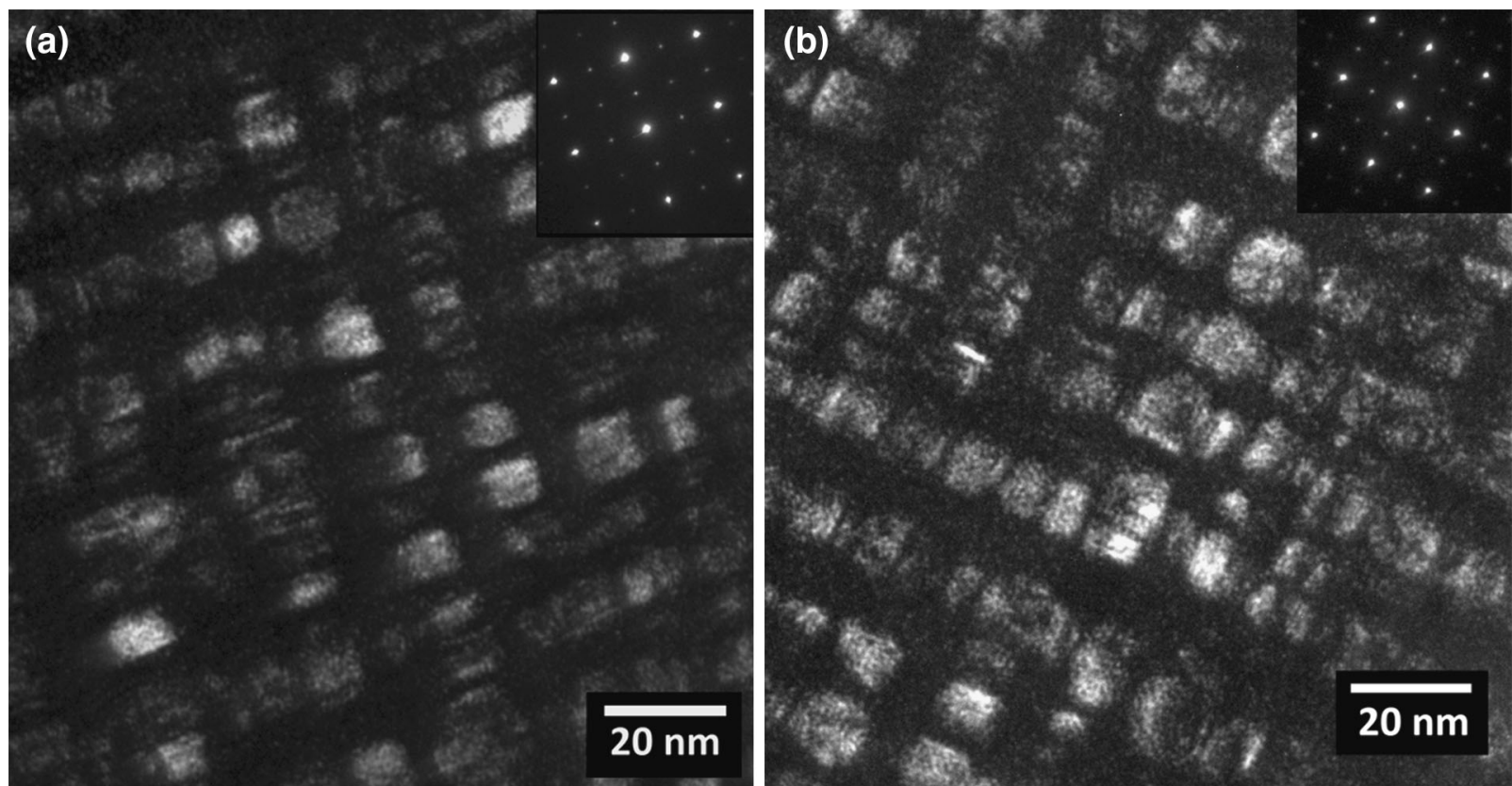

Fig. 3- Dark-field images of the (a) $1.07 \mathrm{pct} \mathrm{Si}$ and (b) $1.56 \mathrm{pct} \mathrm{Si}$ specimens that were aged for $100 \mathrm{~h}$ at $803 \mathrm{~K}\left(530{ }^{\circ} \mathrm{C}\right)$ show $\kappa$-carbide as cuboidal particles that are preferentially coarsening into plates along cube directions. (a) $\kappa$-carbides in the 1.07 pct $\mathrm{Si}$ specimen are an average size of $10 \mathrm{~nm}$ cube length with an average center-to-center particle spacing along cube directions of $16 \mathrm{~nm}$. (b) $\kappa$-carbides are larger in the $1.56 \mathrm{pct} \mathrm{Si}$ specimen and are an average size of $12 \mathrm{~nm}$ with an center-to-center particle spacing along a cube direction of $20 \mathrm{~nm}$.

directions, which is evidence of closely spaced satellite reflections and an advanced stage of spinodal decomposition along cube directions. Diffraction intensity concentrated into satellite reflections parallel with 020 in the $B=$ [101] diffraction pattern of the $1.56 \mathrm{pct}$ Si specimen is shown in Figure 2(d).

Figures 3(a) and (b) show the $1.07 \mathrm{pct}$ Si and $1.56 \mathrm{pct}$ $\mathrm{Si}$ specimens that were solution treated and aged for 100 hours at $803 \mathrm{~K}\left(530{ }^{\circ} \mathrm{C}\right)$. Increasing the aging temperature increases the kinetics of particle coarsening and the $\kappa$-carbides appear as much larger cuboidal particles that are an average size of $10 \mathrm{~nm}$ in the $1.07 \mathrm{pct}$ Si alloy (Figure 3(a)) and $12 \mathrm{~nm}$ in the $1.56 \mathrm{pct}$ Si alloy (Figure 3(b)) as measured along a cube edge. The $\kappa$-carbides are periodically arranged along cube directions and the average wavelength of the spacing along $\langle 100\rangle$ was $16 \mathrm{~nm}$ for the 1.07 pct $\mathrm{Si}$ specimen and 20 to $25 \mathrm{~nm}$ in the 1.56 pet Si specimen.

\section{B. X-ray Diffraction}

X-ray diffraction patterns for the $0.59 \mathrm{pct} \mathrm{Si}$ and 1.56 pct $\mathrm{Si}$ specimens, aged for 48 hours at $843 \mathrm{~K}$ $\left(570{ }^{\circ} \mathrm{C}\right)$, are shown in Figures 4(a) and (b). Reflections corresponding to $\beta-\mathrm{Mn}, \mathrm{B}_{2}$, or $\mathrm{D}_{3}$ phases were not detected in the X-ray diffraction patterns and TEM analysis showed only a microstructure consisting of austenite and $\kappa$-carbide as shown in Figures 4(a) and 3, respectively. A detail view of the austenite and $\kappa$-carbide (200) diffraction intensity is given in Figure 4(b) and the amount of $\kappa$-carbide precipitation appears to be independent of silicon content. Table II gives the calculated values of the austenite and $\kappa$-carbide lattice parameter as a function of aging and silicon addition. The austenite lattice parameter slightly decreased with increasing silicon content for both specimens aged at $803 \mathrm{~K}$ and $843 \mathrm{~K}\left(530{ }^{\circ} \mathrm{C}\right.$ and $\left.570{ }^{\circ} \mathrm{C}\right)$. Increasing the amount of silicon from 0.59 to 1.56 pct Si slightly increased the lattice parameter of $\kappa$-carbide from 0.372 to $0.373 \mathrm{~nm}$ for specimens aged for 48 hours at $843 \mathrm{~K}\left(570{ }^{\circ} \mathrm{C}\right)$. Because of extensive peak broadening in the XRD pattern of the $1.56 \mathrm{pct} \mathrm{Si}$ specimen that was aged for 60 hours at $803 \mathrm{~K}\left(530^{\circ} \mathrm{C}\right), \kappa$-carbide could not be distinguished from the fundamental austenite peaks. Table II shows that as the amount of silicon increased, the lattice parameter of the austenite decreases with a simultaneous increase in the $\kappa$-carbide lattice parameter. This induces a higher degree of lattice mismatch between the two phases as the silicon content is increased.

\section{Atom-Probe Tomography}

APT analyses were performed to determine the effect of silicon on the size, distribution, and chemical composition of $\kappa$-carbide precipitates. Specimens were prepared from steels with $0.59 \mathrm{pct}$ and $1.56 \mathrm{pct}$ Si that were aged for 60 hours at $803 \mathrm{~K}\left(530^{\circ} \mathrm{C}\right)$. An aging temperature of $803 \mathrm{~K}\left(530^{\circ} \mathrm{C}\right)$ was chosen to be consistent with mechanical property data and a condition of peak hardness at 60 hours. Virtual, rectangular, "slices" oriented with respect to the preferential direction of the precipitate alignment (100) were created with the IVAS software to allow for a direct visualization of the precipitation microstructure. The $\kappa$-carbides were discriminated from the matrix austenite by a 4 at. pct $C$ isoconcentration surface obtained with a voxel size of $1 \mathrm{~nm}$ and a delocalization of $3 \mathrm{~nm}$. The 4 at. pct isoconcentration threshold was chosen because it 


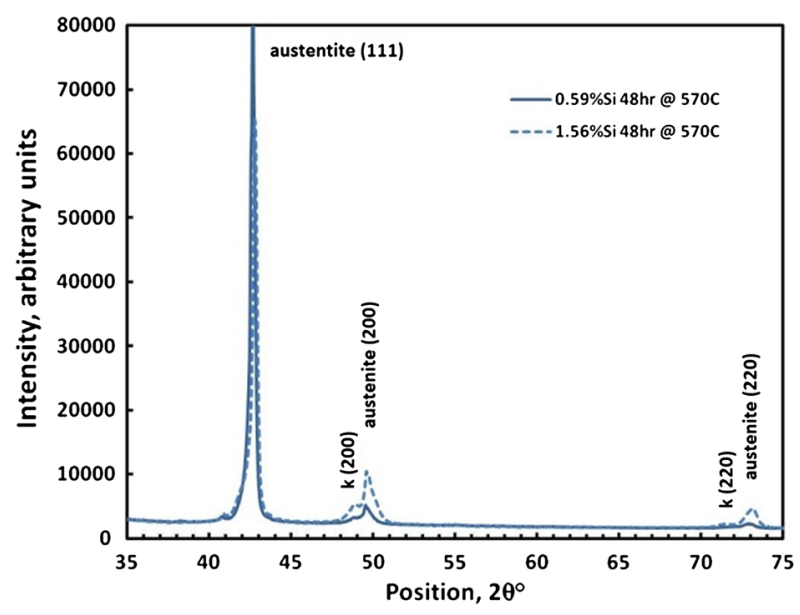

(a)

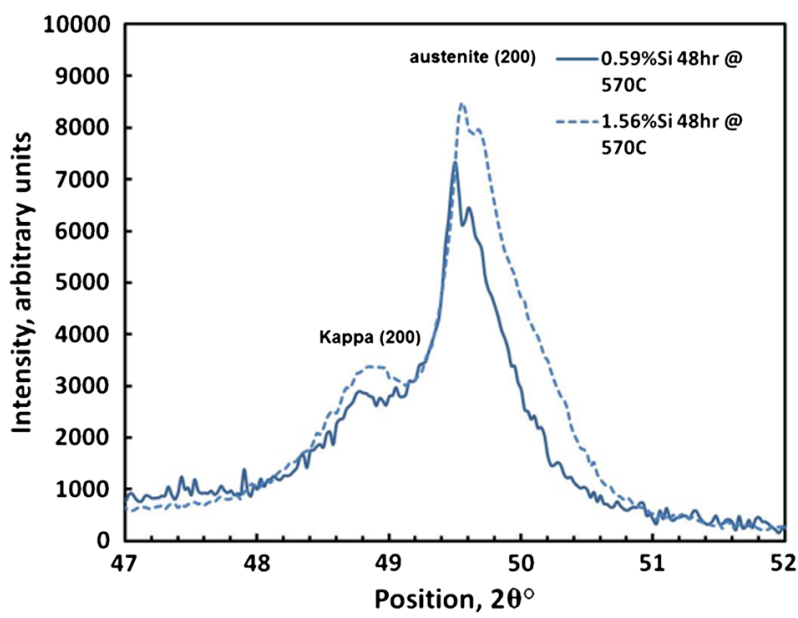

(b)

Fig. $4-(a)$ The XRD patterns for the 0.59 pct $\mathrm{Si}$ and 1.56 pet $\mathrm{Si}$ low phosphorus containing $(<0.003$ pct $\mathrm{P})$ specimens show only austenite and $\kappa$-carbide peaks after aging for $48 \mathrm{~h}$ at $843 \mathrm{~K}\left(570{ }^{\circ} \mathrm{C}\right)$. (b) Detail image of the austenite and $\kappa$-carbide (200) peaks from (a) shows that there is little difference in the amount of $\kappa$-carbide precipitation with silicon addition. The split in the main austenite peak is a sideband resulting from the difference in austenite lattice parameter as carbon is removed from solution during the spinodal decomposition process.

Table II. Austenite and $\boldsymbol{\kappa}$-Carbide Lattice Parameters Measured by XRD

\begin{tabular}{lcccc}
\hline $\begin{array}{l}\text { Weight } \\
\text { Percent Si }\end{array}$ & Heat Treatment & $a^{\gamma}(\mathrm{nm})$ & $a^{\kappa}(\mathrm{nm})$ & $\begin{array}{c}\text { Percentage } \\
\text { Mismatch }\end{array}$ \\
\hline 0.59 & Aged 60 h at & 0.3681 & 0.3712 & 0.84 \\
1.56 & $803 \mathrm{~K}\left(530^{\circ} \mathrm{C}\right)$ & 0.3673 & & \\
0.59 & Aged 48 h @ & 0.3666 & 0.3718 & 1.41 \\
1.56 & $843 \mathrm{~K}\left(570^{\circ} \mathrm{C}\right)$ & 0.3659 & 0.3731 & 1.97 \\
\hline
\end{tabular}

represents the rounded midpoint concentration between the carbon maximum and minimum concentrations in the precipitates and the matrix. Figures 5(a) and (b) show the reconstruction slices of the 60 hours aged 0.59 pct $\mathrm{Si}$ and $1.56 \mathrm{pct} \mathrm{Si}$ specimens. $\kappa$-carbide is shown as an interconnected structure modulated along the crystallographic cube directions rather than with a cuboidal morphology. The volume fraction of $\kappa$-carbide was determined to be 0.19 for the 0.59 pct $\mathrm{Si}$ specimen and 0.18 for the $1.56 \mathrm{pct} \mathrm{Si}$ specimen and was calculated by summing the total number of atoms contained within the isoconcentration surfaces $v s$ the total number of matrix atoms. Molar volumes for the respective phases were calculated from the measured lattice parameters. The lattice parameter of $\kappa$-carbide in the $1.56 \mathrm{pct} \mathrm{Si}$ specimen was assumed to be similar to the 0.59 pct $\mathrm{Si}$ specimen and was estimated to be $0.3712 \mathrm{~nm}$.

A concentration profile traversing the austenite matrix and the $\kappa$-carbides for the $1.56 \mathrm{pct}$ Si specimen, aged for 60 hours at $803 \mathrm{~K}\left(530^{\circ} \mathrm{C}\right)$, was generated by positioning a $4 \mathrm{~nm}$ diameter virtual cylinder across a group of precipitates as shown in Figure 6(a). The concentration of carbon, aluminum, manganese, and iron through areas of $\kappa$-carbide and matrix austenite, which is "cut" by the continuous virtual cylinder, is shown to be consistent with a wave-like decomposition profile with an average wavelength of 14 or $15 \mathrm{~nm}$ as shown in Figure 6(b). $\kappa$-carbide precipitates are the carbon-rich regions of the modulated structure enriched with as much as 9 at. pct $\mathrm{C}$ and 24 at. pct $\mathrm{Al}$ and depleted in manganese and iron. A sinusoidal composition profile with a diffuse interface between the " $k$-carbide" (ordered regions) and the matrix is indicative of spinodal decomposition. The matrix areas between the $\kappa$-carbides are shown to be depleted in carbon and aluminum to levels as low as 0.8 and 12 at. pct, respectively.

The concentration distribution can also be analyzed utilizing a $2 \mathrm{D}$ concentration contour plot as shown in Figure 7 for the 60 hours aged 1.56 pct Si specimen. Contour plots for carbon (color scale from 2 to 6 at. pct) and aluminum (from 15 to 21 at. pct) are shown in Figures 7(a) and (b), respectively, and were produced using a $2 \mathrm{~nm}$ virtual slice across the $\mathrm{z}$-axis of the box reconstruction volume in Figure 5(b). $\kappa$-carbide is shown to be rich in both carbon and aluminum and the diffuse interface between the matrix and the $\kappa$-carbide in Figure 7(a) is typical of phase transformations resulting from spinodal decomposition. A one dimensional representation of the carbon concentration profile across the $\mathrm{x}$-axis of Figure 7(a) is shown in Figure 7(c). The carbon profile is clearly wave-like and consists of many sinusoidal concentration waves that are superimposed upon one another. The average wavelength of the carbon concentration profile was determined to be $15 \mathrm{~nm}$.

A more quantitative analysis of the alloy partitioning between the matrix and the $\kappa$-carbide was achieved by utilizing a proximity histogram concentration profile, or proxigram for short. ${ }^{[30]}$ The proxigram gives the solute concentration as a function of distance from the 4 at. pct $\mathrm{C}$ isoconcentration surfaces which delineate the $\kappa$-carbide from the matrix austenite. Some advantages of this method are that it can accommodate the curvature of nonplanar interfaces and the results can be averaged over all the isosurfaces to reduce statistical error. ${ }^{[31]}$ The proximity histogram concentration profiles of $\mathrm{Fe}, \mathrm{Mn}, \mathrm{Al}, \mathrm{C}, \mathrm{Si}, \mathrm{Mo}$, and $\mathrm{P}$ were determined as a function of distance from the 4 at. pct $\mathrm{C}$ isoconcentration surfaces. Concentration profiles across the interface 


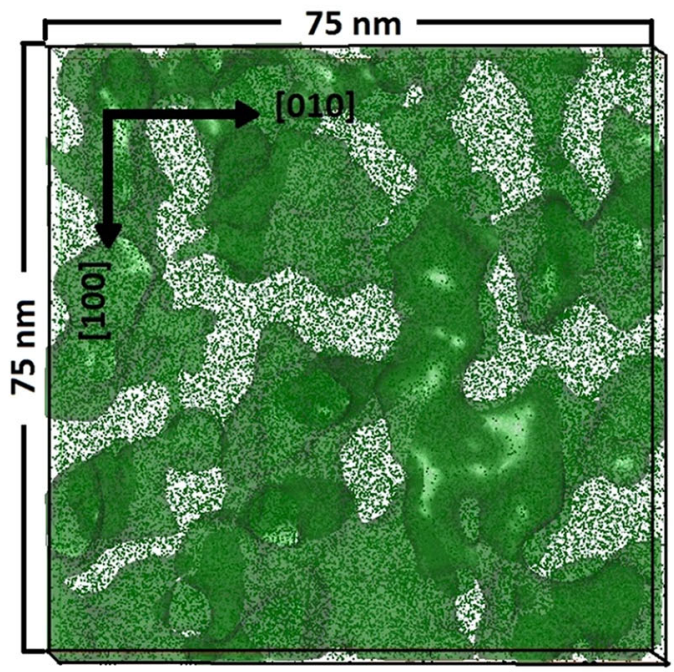

(a)

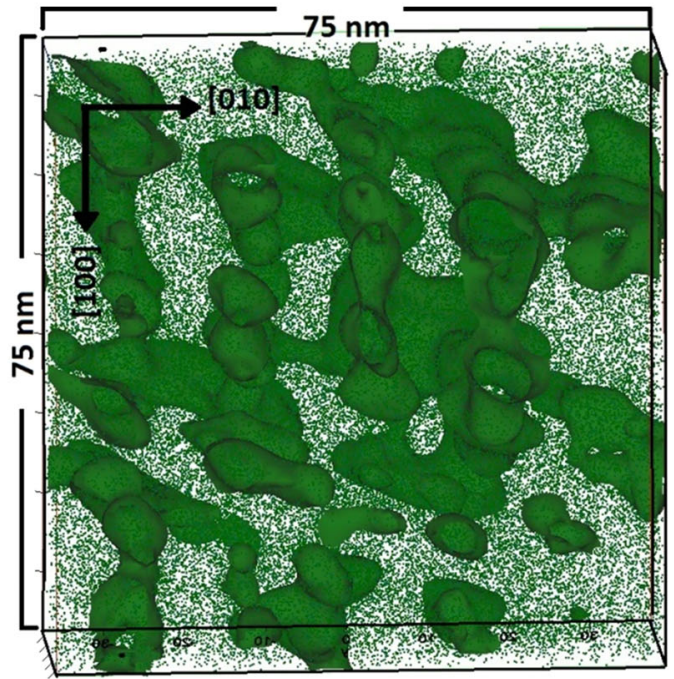

(b)

Fig. 5- Virtual slices from a larger APT reconstruction volume corresponding to the $(a) 0.59 \mathrm{pct} \mathrm{Si}$ steel $(0.002 \mathrm{pct} \mathrm{P})$ and the $(b) 1.56 \mathrm{pct} \mathrm{Si}$ steel aged for $60 \mathrm{~h}$ at $803 \mathrm{~K}\left(530^{\circ} \mathrm{C}\right.$ ) showing 50 pct of the total carbon atoms (green dots). The 4 at. pct $\mathrm{C}$ isoconcentration surfaces delineate $\kappa$-carbide from the matrix. The volume fraction of $\kappa$-carbide is 0.19 and 0.18 for the 0.59 and 1.56 pct Si specimens, respectively. Slice depth in both reconstructions is $25 \mathrm{~nm}$.

of the $\kappa$-carbide for the $0.59 \mathrm{pct} \mathrm{Si}$ and $1.56 \mathrm{pct} \mathrm{Si}$ alloys which were aged for 60 hours at $803 \mathrm{~K}\left(530^{\circ} \mathrm{C}\right)$ are shown in Figure 8. Adding silicon is shown to have little effect on the manganese distribution and the $\kappa$-carbide is shown to be slightly depleted in manganese for both silicon-containing specimens as shown in Figures 8(a) and (b). However, increasing the amount of silicon from 0.59 pct to 1.56 pct $\mathrm{Si}$ was shown to increase the amplitude of carbon between the matrix and the $\kappa$-carbide by almost 1.5 at. pct as shown in Figure 8(c) and (d). The aluminum peak concentration in the $\kappa$-carbide appears to be slightly higher in the $1.56 \mathrm{pct}$ Si-containing steel.

The $\kappa$-carbide is depleted of silicon during aging and increasing the amount of silicon results in the matrix of the 1.56 pct $\mathrm{Si}$ steel being enriched with as much as 4 at. pet $\mathrm{Si}$ after aging for 60 hours at $803 \mathrm{~K}\left(530^{\circ} \mathrm{C}\right)$. It is interesting to note that molybdenum is slightly enriched in the $\kappa$-carbide of the $1.56 \mathrm{pct} \mathrm{Si}$ specimen as shown in Figure 8(d). Phosphorus appears to be homogeneously distributed throughout both phases in both steels. However, the low concentration of $\mathrm{P}$ made an accurate determination of small changes in phosphorus distribution difficult to quantify as the counting statistics deteriorates with increasing distance from the isoconcentration surface. The $\kappa$-carbide and matrix compositions are given in Table III and were determined from the average compositions of the plateau regions of the proxigrams as per Miller and Forbes. ${ }^{[31]}$ Increasing the amount of silicon increased the amount of carbon in the $\kappa$-carbide from 5.3 to 6.6 at. pct and decreased the carbon concentration in the matrix from 2.5 and 2.3 at. pet.

The results of the current study show that after 60 hours of aging at $530{ }^{\circ} \mathrm{C}, \kappa$-carbide is substoichiometric and may be expressed as $(\mathrm{Fe}, \mathrm{Mn})_{3} \mathrm{AlC}_{x}$ with $x=0.3$. Partitioning of alloying elements between the $\kappa$-carbide and the matrix was quantified using the partitioning ratio, the ratio of atomic concentration in the precipitate divided by the atomic concentration of the matrix. A partitioning ratio or coefficient greater than one indicates partitioning of the solute species to the $\kappa$-carbide phase while a value less than one indicates partitioning of solute species to the austenite matrix during aging. Partitioning ratios of solute atoms as determined from APT analysis are given in Table IV. Silicon content is shown to have no effect on the partitioning of manganese and manganese partitioning ratios of 0.9 were determined for all the alloys. However, increasing the amount of silicon from 0.59 to $1.56 \mathrm{pct} \mathrm{Si}$ was shown to increase the carbon partitioning ratio from 2.1 to 2.9. Silicon was shown to strongly partition to the matrix with a partitioning ratio of 0.6 to 0.7 . Aluminum was concentrated within the $\kappa$-carbide with a partitioning ratio of 1.2 to 1.3 and was insensitive to silicon content. Molybdenum is shown to be significantly more highly enriched in the $\kappa$-carbide of the 1.56 pet Si specimen with a partitioning ratio of 2.1.

\section{First-Principles Modeling}

To elucidate the $\mathrm{Si}$ effect in these alloys, firstprinciples electronic structure calculations were performed. For this, the Vienna ab initio simulation package VASP ${ }^{[32,33]}$ was utilized in the projector augmented waves (PAW) formalism and with the generalized gradient approximation (GGA) for the exchange-correlation functional. ${ }^{[34]}$ Calculations were performed for the ferromagnetic high-spin state (FM/HS) of fcc Fe and the equilibrium lattice parameter was determined to be $0.364 \mathrm{~nm}$ with a magnetic moment of $2.52 \mu_{\mathrm{B}}$, which is in good agreement with previous 


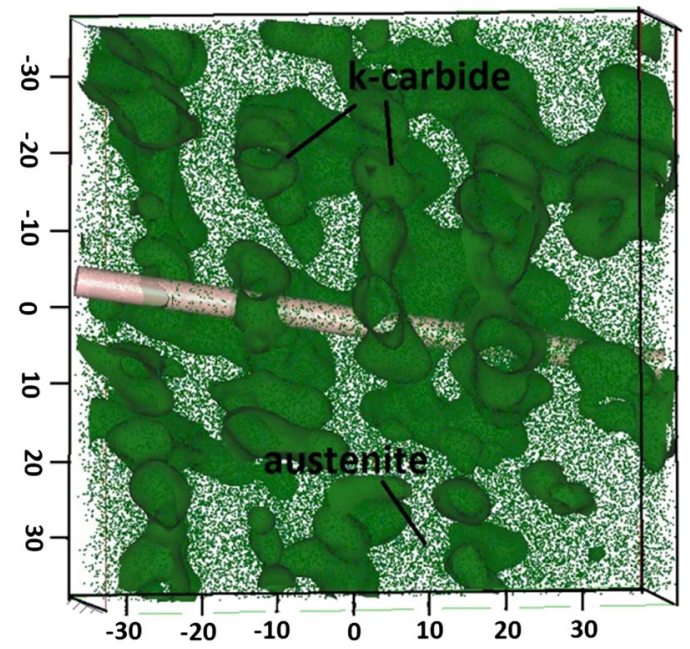

(a)

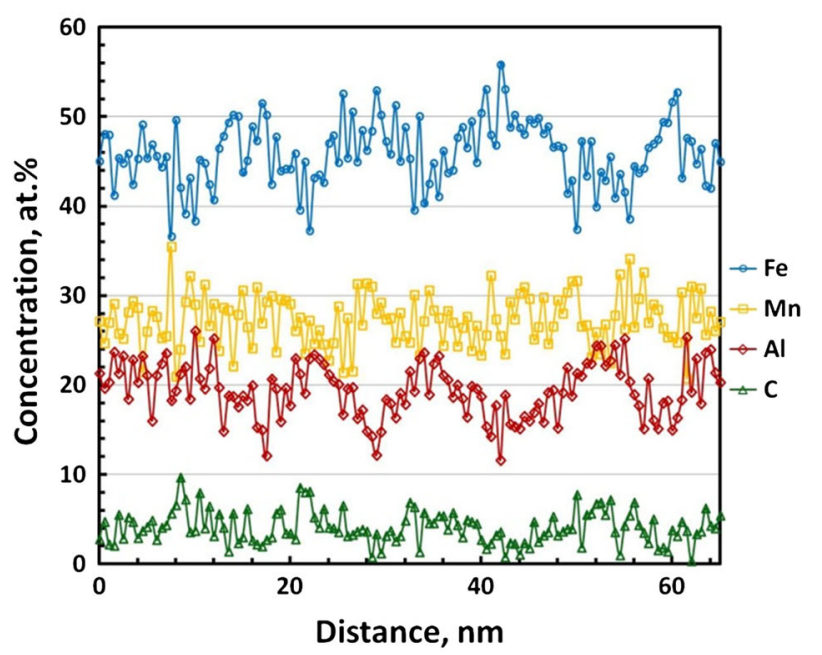

(b)

Fig. 6- (a) A reconstruction "slice" of the 1.56 pet Si specimen which was aged for $60 \mathrm{~h}$ at $803 \mathrm{~K}\left(530^{\circ} \mathrm{C}\right)$ shows the location of the $4 \mathrm{~nm}$ diameter virtual cylinder which was used to generate the concentration profile in $(b)$. (b) The concentration profile appears wavelike and without sharp boundaries between the matrix and the $\kappa$-carbide. $\kappa$-carbide is enriched with carbon aluminum and depleted in manganese and iron.

$a b$ initio calculations. ${ }^{[35]}$ Silicon addition was modeled using a 32-atom supercell for fcc iron and 40-atom supercell composed of 8 unit cells for $\kappa$-carbide. It was determined that at a silicon impurity of 3 at. pct concentration (Fe31Si) slightly decreases the lattice parameter of both nonmagnetic (NM) and ferromagnetic (FM) fcc Fe austenite from $0.3450 \mathrm{~nm}(\mathrm{NM})$ and $0.3641 \mathrm{~nm}(\mathrm{FM})$ to $0.3431 \mathrm{~nm}(\mathrm{NM})$ and $0.3622 \mathrm{~nm}$ (FM). This small decrease of the lattice parameter with $\mathrm{Si}$ addition agrees well with the experimental findings reported in Table $\mathrm{V}$, where $a^{\gamma}$ reduces by approximately 0.2 pct per 1 wt pet $\mathrm{Si}$. The calculated changes in the enthalpy of formation $(\Delta H)$ are negative upon 3 at. pct Si substitution $(-43$ and $-50 \mathrm{meV} /$ atom for $\mathrm{NM}$ and FM states, respectively). This points out a stabilizing effect of silicon on the austenite phase. Here, it should be noted that silicon is known as a strong stabilizer of ferrite, and the Fe-Si phase diagram contains B2 phase up to 30 pct $\mathrm{Si}$. For austenitic $\mathrm{Fe}_{0.97} \mathrm{Si}_{0.03} \mathrm{C}_{0.03}$ (Fe31SiC), where carbon is in an octahedral interstitial site and silicon substitutes for iron atoms in the nearest neighbor, (NN), next nearest neighbor (NNN), or most remote positions from carbon, the total energy comparison reveals that silicon prefers to replace $\mathrm{Fe}$ atoms far from carbon with a large energy gain of $-0.93 \mathrm{eV}$. The Si-C binding energy estimated from total energies of supercells as $E_{\mathrm{b}}=[E(\mathrm{Fe} 32 \mathrm{C})+E(\mathrm{Fe} 31 \mathrm{Si})]-$ $[E(\mathrm{Fe} 31 \mathrm{SiC})+E(\mathrm{Fe} 31)]$ is equal to -0.87 and $-0.06 \mathrm{eV}$ for the $\mathrm{NN}$ and $\mathrm{NNN}$ atoms, respectively (here negative $E_{\mathrm{b}}$ corresponds to repulsion, whereas positive $E_{b}$ means attraction between $\mathrm{Si}$ and $\mathrm{C}$ atoms).

Therefore, the interaction between the nearest silicon and carbon atoms is strongly repulsive and, hence, it prevents $\mathrm{C}$ from occupying the NN positions with $\mathrm{Si}$. However, the magnitude of $E_{\mathrm{b}}$ decreases sharply for the NNN Si and $\mathrm{C}$ atoms making this distribution much more favorable than the formation of NN Si-C pair. The negative binding energies were also obtained for the C-C pairs in fcc $\mathrm{Fe}$, but in this case a repulsive interaction is weaker $(-0.15$ and $-0.08 \mathrm{eV}$ between carbon atoms located in the NN and NNN octahedral interstitials, respectively) and decreases slowly with the $\mathrm{C}-\mathrm{C}$ distance. ${ }^{[33]}$

The ground state of $\mathrm{Fe}_{3} \mathrm{AlC}$ was obtained to be $\mathrm{FM}$ with an equilibrium lattice parameter of $0.3753 \mathrm{~nm}$. These results are in good agreement with previous theoretical results. ${ }^{[37-41]}$ To determine the preferable site for silicon impurity in $\kappa$-carbide, the total energy calculations were performed for $\mathrm{Fe}_{2.875} \mathrm{Si}_{0.125} \mathrm{AlC}(\mathrm{Fe} 23$ $\mathrm{SiA} 18 \mathrm{C} 8)$ and $\mathrm{Fe}_{3} \mathrm{Al}_{0.875} \mathrm{Si}_{0.125} \mathrm{C}(\mathrm{Fe} 24 \mathrm{SiA} 17 \mathrm{C} 8)$, where $\mathrm{Si}$ atom replaces the $\mathrm{Fe}$ and $\mathrm{Al}$ atoms, respectively (see Table V). It was found that silicon only slightly changes the lattice parameter of stoichiometric $\kappa$-carbide $(<0.2$ pet for both Fe and Al substitution), which is in agreement with previous experimental observation [36] where the lattice constant of $\mathrm{E} 2{ }_{1}-\mathrm{Fe}_{3} \mathrm{AlC}$ phase does not show a decrease with the addition of Si.

It is predicted that silicon will substitute for aluminum $\left(\mathrm{Si}^{\mathrm{Al}}\right)$ and not for iron $\left(\mathrm{Si}^{\mathrm{Fe}}\right)$ in stoichiometric $\mathrm{Fe}_{3} \mathrm{AlC}$ with the energy preference for $\mathrm{Si}^{\mathrm{Al}}$ with respect to $\mathrm{Si}^{\mathrm{Fe}}$ to be $-35 \mathrm{meV} /$ atom. In stoichiometric $\kappa$-carbide, the changes in the enthalpy of formation $\Delta H$ are positive upon addition of $\mathrm{Si}$ atom, and by comparing $\Delta H$ in austenite $(-50 \mathrm{meV} /$ atom for $\mathrm{FM}$ state) and in stoichiometric $\kappa$-carbide $(+11 \mathrm{meV} /$ atom for $\mathrm{Si}$ at the $\mathrm{Al}$ sites and $+46 \mathrm{meV}$ /atom for $\mathrm{Si}$ at the Fe sites), it can be concluded that $\mathrm{Si}$ should be partitioned to the austenite matrix.

Experimental results demonstrate that $\kappa$-carbide is a nonstoichiometric compound where the carbon deficiency may reach from 50 to 60 pct. ${ }^{[6,42,43]}$ Additional calculations were performed to consider how carbon vacancies may affect the preferable sites of $\mathrm{Si}$ in nonstoichiometric $\kappa$-carbide. For nonstoichiometric $\mathrm{Fe}_{3} \mathrm{AlC}_{0.875}$ ( $\left.\mathrm{Fe} 24 \mathrm{~A} 18 \mathrm{C} 7\right)$, a negligible reduction of the lattice parameter with $\mathrm{Si}$ addition was obtained and with nearly equal substitution energies for Si impurity in the Fe and Al sites (Table VI). Thus, it can be concluded that carbon deficiency in $\kappa$-carbide allows $\mathrm{Si}$ to substitute in either the Fe or Al sites. 


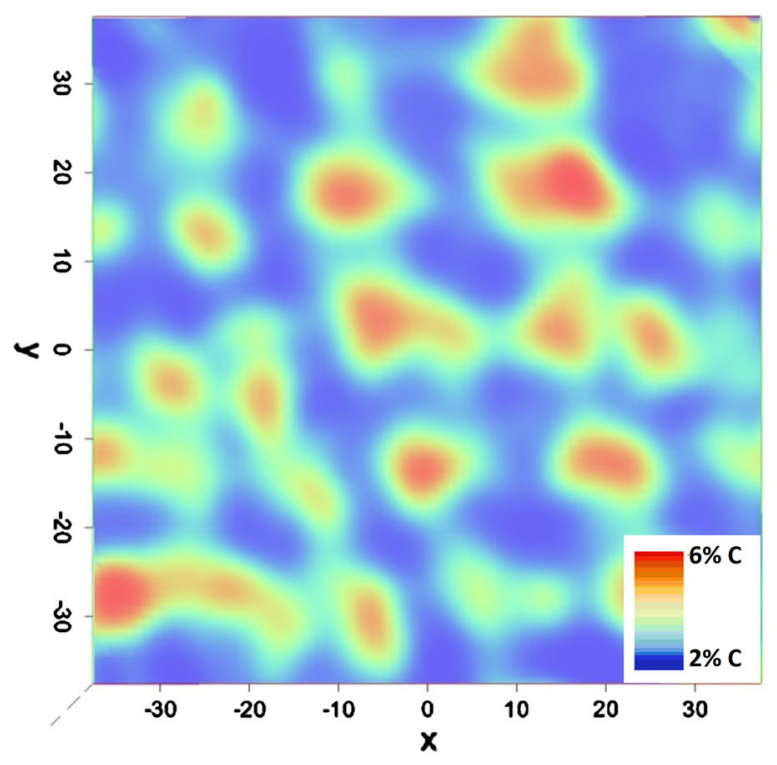

(a)

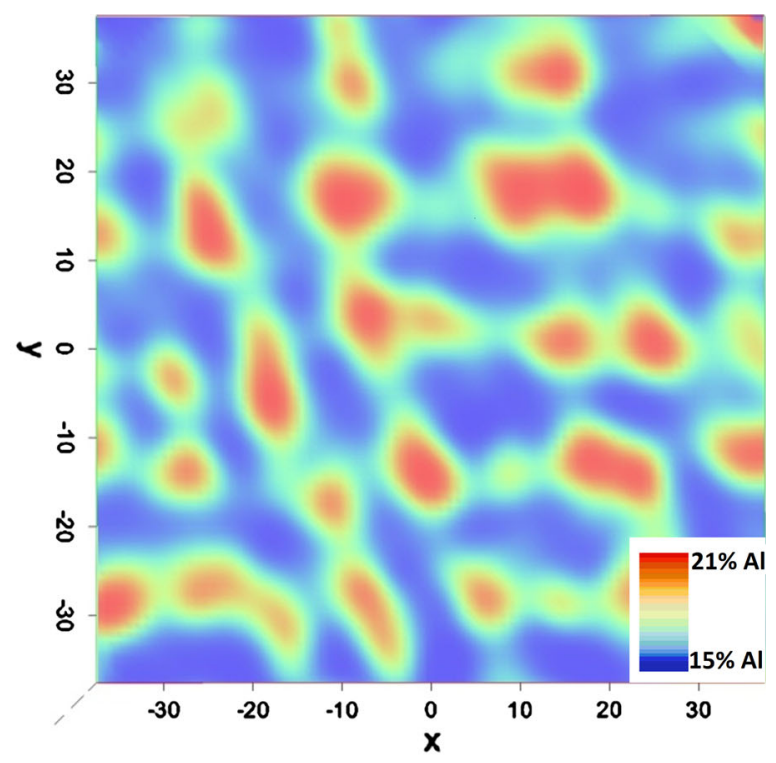

(b)

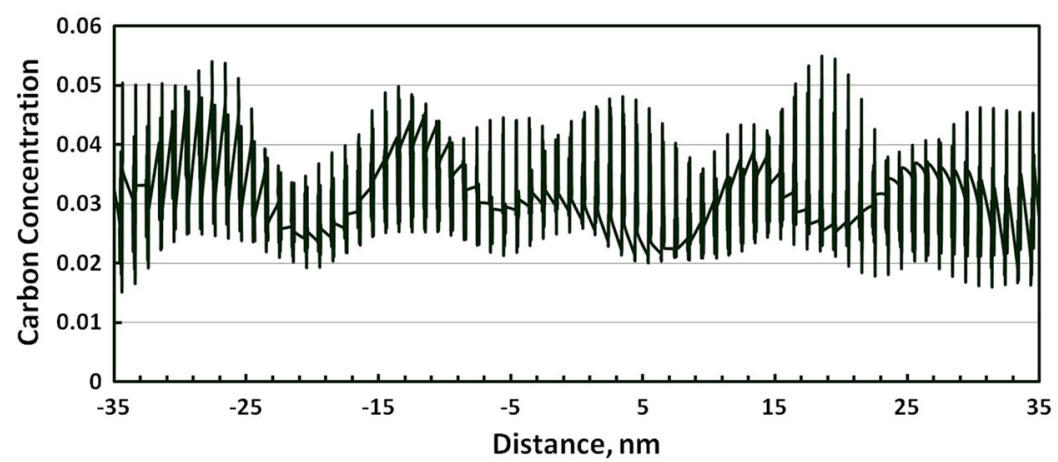

(c)

Fig. 7- (Color figure online) 2D concentration contour plots taken from a 2 nm slice through the $\mathrm{z}$-axis of the reconstruction volume corresponding to the $1.56 \mathrm{pct} \mathrm{Si}$ specimen that was aged for $60 \mathrm{~h}$ at $803 \mathrm{~K}\left(530^{\circ} \mathrm{C}\right)$ show $(a)$ carbon $(2$ to 6 at. pct-blue to red) and $(b)$ aluminum (15 to 21 at. pct-blue to red) "hot spots" that denote the location of $\kappa$-carbides. (c) A one dimensional projection of the distribution of the carbon concentration as a function of distance along the abscissa shows a sinusoidal profile with many composition waves superimposed upon one another.

The lower carbon content in $\kappa$-carbide may lead to the vacancy ordering. Modeling of two carbon vacancies in Fe24A18C6 supercell $\left(\mathrm{Fe}_{3} \mathrm{AlC}_{0.75}\right)$ showed that the $\mathrm{Si}$-vacancy (Si-vac) interaction in $\kappa$-carbide is attractive, which favors formation of the $\langle 100\rangle$ vac-Si ${ }^{\mathrm{Fe}}$-vac, $\langle 110\rangle$ vac-Si ${ }^{\mathrm{Al}}$-vac, and $\langle 111\rangle$ vac-Si ${ }^{\mathrm{Al}}$-vac complexes. The averaged lattice parameter of $\mathrm{Fe}_{3} \mathrm{AlC}_{0.75}$ is equal to $0.3727,0.3723$, and $0.3725 \mathrm{~nm}$ for the $\langle 100\rangle,\langle 110\rangle$, and $\langle 111\rangle$ vacancy ordering, respectively, and $\mathrm{Si}$ addition changes $a^{\mathrm{k}}$ to $0.3736,0.3719$, and $0.3718 \mathrm{~nm}$, when the $\langle 100\rangle$ vac-Si ${ }^{\mathrm{Fe}}$-vac, $\langle 110\rangle$ vac-Si ${ }^{\mathrm{Al}}$-vac, and $\langle 111\rangle$ vac$\mathrm{Si}^{\mathrm{Al}}$-vac complexes are formed in $\mathrm{Fe}_{3} \mathrm{AlC}_{0.75}$. Thus, it is predicted that the $\mathrm{Si}^{\mathrm{Fe}}$ substitution increases the lattice parameter of nonstoichiometric $\kappa$-carbide, while the $\mathrm{Si}^{\mathrm{Al}}$ substitution reduces it.

When $\mathrm{Si}$ replaces $\mathrm{Fe}$ in nonstoichiometric $\kappa$-carbide $\left(\mathrm{Fe}_{2.875} \mathrm{Si}_{0.125} \mathrm{AlC}_{0.75}\right.$ where the vacancies are ordered as $\langle 100\rangle$ vac-Si ${ }^{\mathrm{Fe}}$-vac), the value of $\Delta H$ is negative $(\Delta H=-8 \mathrm{meV} /$ atom $)$ as shown in Table VII, while $\Delta H$ is $+6 \mathrm{meV} /$ atom and $+7 \mathrm{meV} /$ atom for the $\mathrm{Si}^{\mathrm{Al}}$ substitutions $\left(\mathrm{Fe}_{3} \mathrm{Al}_{0.875} \mathrm{C}_{0.75} \mathrm{Si}_{0.125}\right.$ with $\langle 110\rangle$ vac-Si ${ }^{\mathrm{Al}}-$ vac and $\langle 111\rangle$ vac-Si ${ }^{A l}$-vac complexes, respectively). This means that the $\mathrm{Fe}$ site is more preferable than the $\mathrm{Al}$ site for $\mathrm{Si}$ impurity due to formation of the $\langle 100\rangle$ vacancySi-vacancy configuration (i.e., due to the strong attractive interaction for the nearest-neighbor $\mathrm{Si}^{\mathrm{Fe}}$-vacancy). Indeed, the experimental compositions of $\kappa$-carbide obtained by LEAP (Table III) demonstrate a reduction of Fe concentration with increasing silicon content that confirms the above theoretical prediction of the $\mathrm{Fe}$ sublattice for $\mathrm{Si}$ additions. The negative $\Delta \mathrm{H}$ obtained for $\mathrm{Fe}_{2.875} \mathrm{Si}_{0.125} \mathrm{AlC}_{0.75}$ shows that silicon stabilizes $\kappa$-carbide. This stabilizing effect does not exist in stoichiometric $\kappa$-carbide and arises only for carbon occupancy less than 75 at. pct due to the strong Si-vacancy interaction. Nevertheless, the substitution energy for $\mathrm{Si}$ is much lower in fcc phase $(\Delta H=-50 \mathrm{meV} / \mathrm{atom})$ than in $\kappa$-carbide $(\Delta H=-8 \mathrm{meV} /$ atom $)$ and $\mathrm{Si}$ is partitioned mainly in austenite matrix, which agrees with previous chemical analyses $^{[44]}$ and our experimental results. 


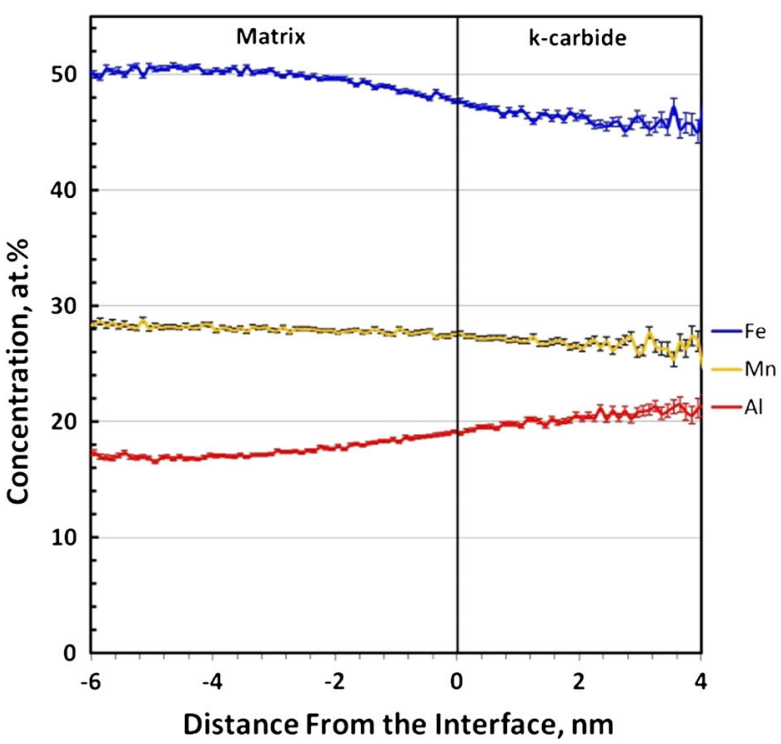

(a)

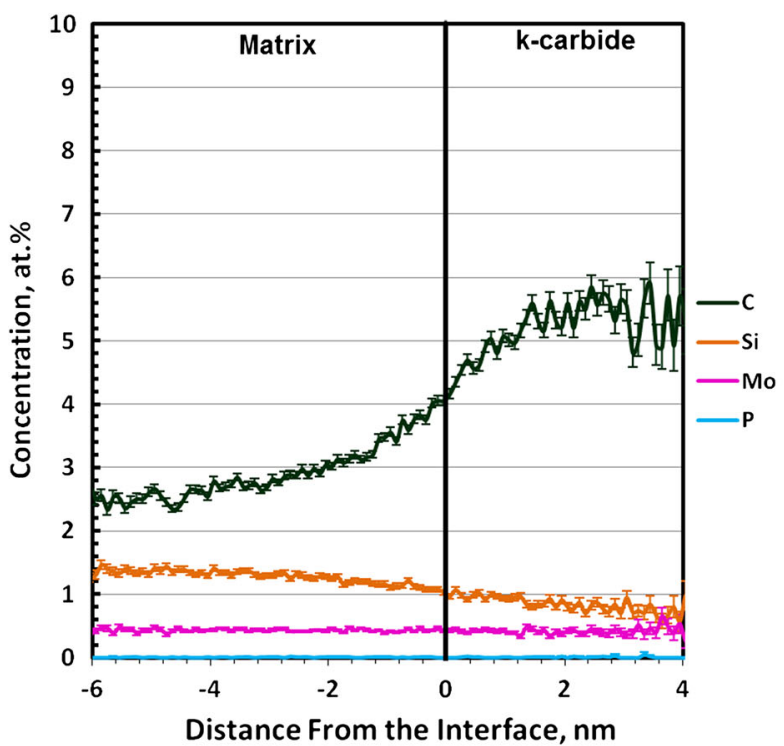

(c)

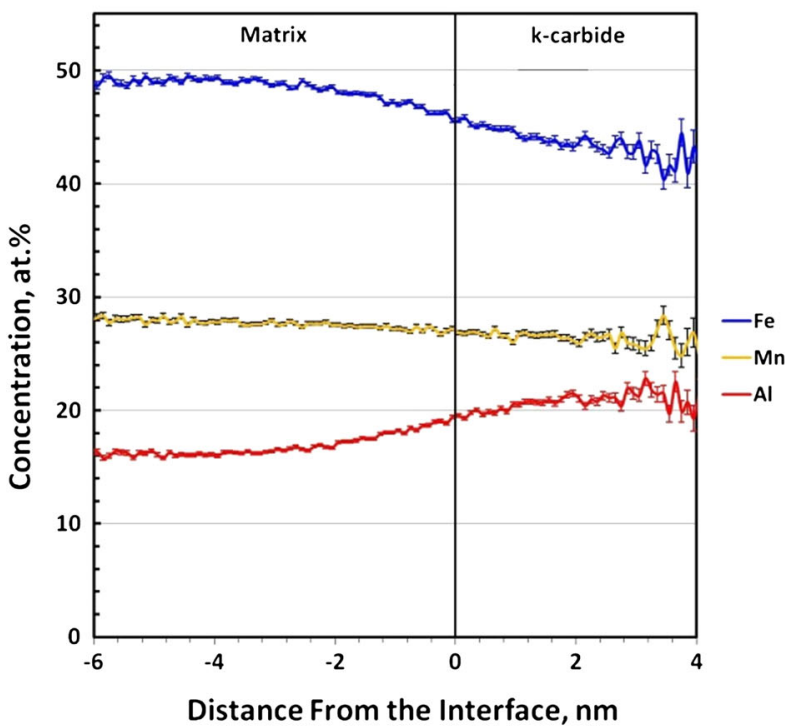

(b)

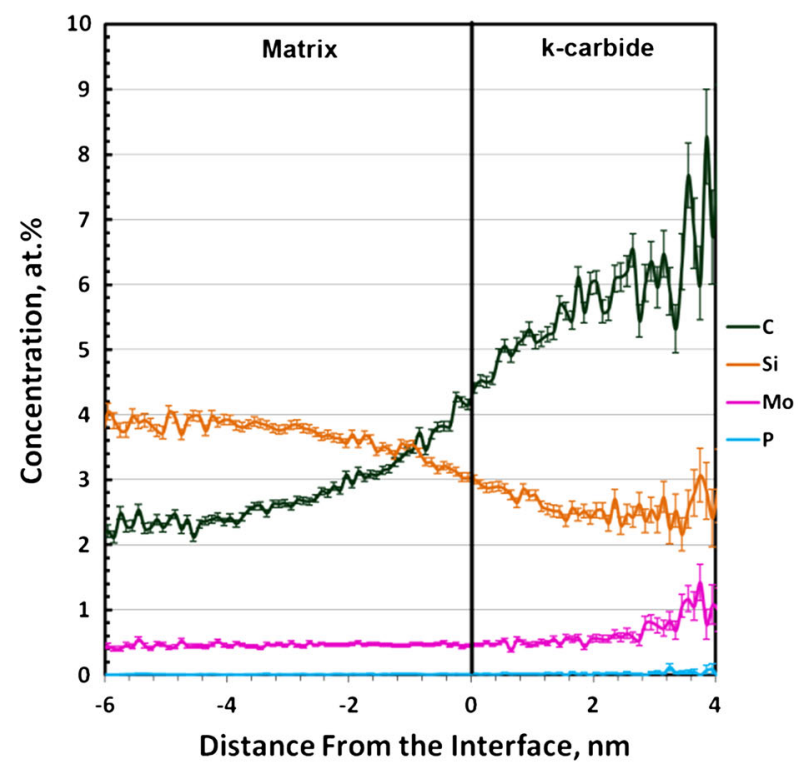

(d)

Fig. 8- Concentration profiles of $\mathrm{Fe}, \mathrm{Mn}$, and $\mathrm{Al}$ with respect to distance from the interface between the $\kappa$-carbide and the austenite matrix for the (a) $0.59 \mathrm{pct} \mathrm{Si}$ and $(b) 1.56 \mathrm{pct} \mathrm{Si}$ steels aged $60 \mathrm{~h}$ at $803 \mathrm{~K}\left(530^{\circ} \mathrm{C}\right)$. Increasing the amount of silicon had no effect on the distribution of manganese and the $\kappa$-carbide was depleted in manganese regardless of the amount of silicon. The concentration profiles of $\mathrm{C}$, $\mathrm{Si}$, Mo, and $\mathrm{P}$ with respect to distance from the interface are shown for the $(c) 0.59 \mathrm{pct} \mathrm{Si}$ and $(d) 1.56 \mathrm{pct} \mathrm{Si}$ steel aged for $60 \mathrm{~h} \mathrm{at} 803 \mathrm{~K}\left(530{ }^{\circ} \mathrm{C}\right)$. Increasing silicon from 0.59 to $1.56 \mathrm{pct} \mathrm{Si}$ increased the amount of carbon in the $\kappa$-carbide during aging by almost 1.0 at. pct. (d) After $60 \mathrm{~h}$ of aging, the matrix is enriched with as much as 4 at. pet $\mathrm{Si}$ in the $1.56 \mathrm{pct} \mathrm{Si}$ steel.

Table III. Compositions of the Austenite and $\kappa$-carbide in Atomic Percent as Determined by APT

\begin{tabular}{|c|c|c|c|c|c|c|c|}
\hline Phase & $\mathrm{Fe}$ & $\mathrm{Mn}$ & $\mathrm{Al}$ & $\mathrm{C}$ & $\mathrm{Si}$ & Mo & $\mathrm{P}$ \\
\hline \multicolumn{8}{|c|}{$0.59 \mathrm{wt}$ pct $\mathrm{Si}$ aged for $60 \mathrm{~h}$ at $803 \mathrm{~K}\left(530^{\circ} \mathrm{C}\right)$} \\
\hline Austenite & $50.0 \pm 0.27$ & $28.4 \pm 0.24$ & $17.0 \pm 0.2$ & $2.51 \pm 0.08$ & $1.36 \pm 0.06$ & $0.43 \pm 0.03$ & $0.005 \pm 0.001$ \\
\hline$\kappa$-carbide & $46.0 \pm 0.77$ & $26.4 \pm 0.68$ & $21.1 \pm 0.63$ & $5.32 \pm 0.34$ & $0.75 \pm 0.13$ & $0.43 \pm 0.10$ & $0.006 \pm 0.005$ \\
\hline \multicolumn{8}{|c|}{$1.56 \mathrm{wt}$ pet $\mathrm{Si}$ aged for $60 \mathrm{~h}$ at $803 \mathrm{~K}\left(530^{\circ} \mathrm{C}\right)$} \\
\hline Austenite & $49.1 \pm 0.28$ & $28.1 \pm 0.26$ & $16.2 \pm 0.21$ & $2.30 \pm 0.09$ & $3.85 \pm 0.11$ & $0.45 \pm 0.04$ & $0.010 \pm 0.006$ \\
\hline$\kappa$-carbide & $42.3 \pm 0.97$ & $26.3 \pm 0.84$ & $21.1 \pm 0.80$ & $6.55 \pm 0.49$ & $2.57 \pm 0.31$ & $0.96 \pm 0.19$ & $0.047 \pm 0.04$ \\
\hline
\end{tabular}


Table IV. Volume Fraction of $\boldsymbol{\kappa}$-carbide and Segregation of Alloying Elements as a Function of Silicon Addition

\begin{tabular}{|c|c|c|c|c|c|c|c|}
\hline \multirow[b]{2}{*}{ Alloy } & \multirow[b]{2}{*}{$V_{\mathrm{f}}^{\kappa}$} & \multicolumn{6}{|c|}{ Partitioning Coefficients } \\
\hline & & $\mathrm{Fe}$ & $\mathrm{Mn}$ & $\mathrm{Al}$ & $\mathrm{C}$ & $\mathrm{Si}$ & Mo \\
\hline 0.59 pet $\mathrm{Si} 60 \mathrm{~h}$ at $803 \mathrm{~K}\left(530^{\circ} \mathrm{C}\right)$ & 0.19 & 0.9 & 0.9 & 1.2 & 2.1 & 0.6 & 1.0 \\
\hline 1.56 pet $\mathrm{Si} 60 \mathrm{~h}$ at $803 \mathrm{~K}\left(530^{\circ} \mathrm{C}\right)$ & 0.18 & 0.9 & 0.9 & 1.3 & 2.9 & 0.7 & 2.1 \\
\hline
\end{tabular}

Table V. The Lattice Parameter $a$ and Changes in the Enthalpy of Formation $\Delta H$ for the Si Substitutions in Stoichiometric $\mathrm{Fe}_{3} \mathrm{AlC}$

\begin{tabular}{llcc}
\hline & $\mathrm{Fe}_{3} \mathrm{AlC}$ & $\mathrm{Fe}_{2.875} \mathrm{Si}_{0.125} \mathrm{AlC}$ & $\mathrm{Fe}_{3} \mathrm{Al}_{0.875} \mathrm{Si}_{0.125} \mathrm{C}$ \\
\hline$a(\mathrm{~nm})$ & 0.3753 & 0.3748 & 0.3746 \\
$\Delta H$ & 0 & +46 & +11 \\
(meV/atom) & & & \\
\hline
\end{tabular}

Table VI. The Lattice Parameter $a$ and Changes in the Enthalpy of Formation, $\Delta H$, for the Si Substitutions in Nonstoichiometric $\mathrm{Fe}_{3} \mathrm{AlC}$.8.87

\begin{tabular}{lccc}
\hline & & $\mathrm{Fe}_{2.875} \mathrm{Si}_{0.125}$ & $\mathrm{Fe}_{3} \mathrm{Al}_{0.875}$ \\
& $\mathrm{Fe}_{3} \mathrm{AlC}_{0.875}$ & $\mathrm{AlC}_{0.875}$ & $\mathrm{C}_{0.875} \mathrm{Si}_{0.125}$ \\
\hline$a(\mathrm{~nm})$ & 0.3740 & 0.3735 & 0.3734 \\
$\Delta H(\mathrm{meV}$ /atom) & 0 & +11 & +8 \\
\hline
\end{tabular}

Table VII. The Lattice Parameter $a$ and Changes in the Enthalpy of Formation $\Delta H$ for the Si Substitutions in Nonstoichiometric $\mathrm{Fe}_{3} \mathrm{AlC}_{0.75}$ with $\langle 100\rangle$ Vacancy Ordering

\begin{tabular}{lcc}
\hline & $\mathrm{Fe}_{3} \mathrm{AlC}_{0.75}$ & $\mathrm{Fe}_{2.875} \mathrm{Si}_{0.125} \mathrm{AlC}_{0.75}$ \\
\hline$a(\mathrm{~nm})$ & 0.3727 & 0.3736 \\
$\Delta H(\mathrm{meV} /$ atom $)$ & 0 & -8 \\
\hline
\end{tabular}

\section{E. Thermodynamic Modeling}

FACTSage thermodynamic modeling software was utilized to determine the effect of silicon addition on the equilibrium amount of $\kappa$-carbide in a Fe-30Mn-9Al$0.9 \mathrm{C}-0.5 \mathrm{Mo}$ alloy. $\kappa$-carbide was modeled as a solid solution carbide, $(\mathrm{Fe}, \mathrm{Mn})_{3} \mathrm{AlC}_{x}$. The results are shown in Figure 9 for silicon additions of 0.5 and 1.5 pct. It is shown that additions of silicon stabilize $\kappa$-carbide to higher temperatures. However, the equilibrium amount of $\kappa$-carbide can be considered to be insensitive to silicon content at temperatures less than $723 \mathrm{~K}\left(500{ }^{\circ} \mathrm{C}\right)$ with a composition of $15 \mathrm{wt}$ pct $\kappa$-carbide. Silicon was shown to stabilize $\kappa$-carbide by increasing the activity of carbon in austenite and thus decreasing the solubility of $\kappa$ carbide in austenite.

\section{DISCUSSION}

Silicon was shown to slightly increase the size of $\kappa$-carbide precipitates and accelerate decomposition kinetics during both early and later stages of aging as

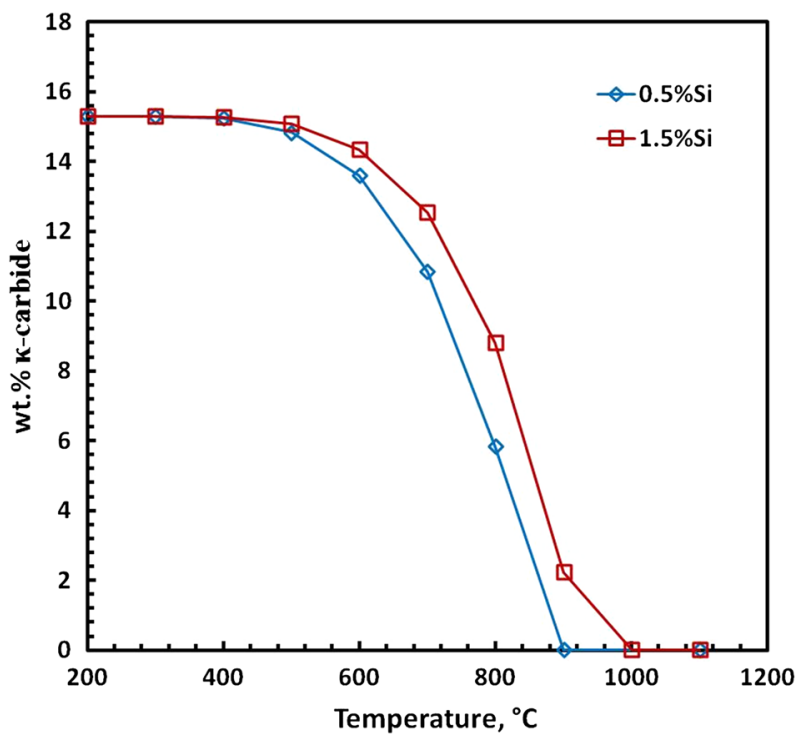

Fig. 9- Thermodynamic modeling of the effect of silicon additions of 0.5 and 1.5 pct $\mathrm{Si}$ on the equilibrium composition of a Fe-30Mn9Al-0.9C-0.5Mo alloy shows an increase in the stability of $\kappa$-carbide with increasing silicon addition.

shown in Figures 2 and 3, respectively. Increasing the amount of silicon led to an increase in the wavelength, measured as the center-to-center distance, of $\kappa$-carbide spacing along $\langle 100\rangle$ from 15 to greater than $20 \mathrm{~nm}$ (Figure 3) for specimens aged for 100 hours at $803 \mathrm{~K}$ $\left(530^{\circ} \mathrm{C}\right)$. The measured wavelengths of modulated $\kappa$-carbide in the current study are consistent with previous results by Sato et al. in which the wavelength was determined to be between 10 and $35 \mathrm{~nm}$ for Fe-(30-34)Mn-(8-11)Al-(0.9-1.0)C alloys aged for $216 \mathrm{~h}$ at $823 \mathrm{~K}\left(550{ }^{\circ} \mathrm{C}\right) .{ }^{[6]}$ The wavelength has been shown to increase with aging time ${ }^{[6,15,45]}$ and this suggests that the 1.56 pct Si specimen that was aged for $100 \mathrm{~h}$ at $803 \mathrm{~K}$ $\left(530{ }^{\circ} \mathrm{C}\right)$ is in a more advanced stage of decomposition than the 1.07 pet $\mathrm{Si}$ specimen as shown in Figures 3(a) and (b), respectively. Han et al.$^{[12]}$ report that diffraction satellites form as result of lattice carbon composition fluctuations along $\langle 100\rangle$ (spinodal decomposition) while the presence of $\mathrm{E} 22_{1}$ superlattice reflections is from concurrent ordering of $\mathrm{C}$ and $\mathrm{Al}$. The presence of satellite intensity around austenite reflections and the simultaneous existence of E2 1 superlattice reflections, as shown in Figure 2, suggest that spinodal decomposition occurs concurrently with ordering of carbon and aluminum. These results are consistent with the work of others suggesting that spinodal decomposition and ordering are concomitant in Fe-Mn-Al-C alloys. ${ }^{[6,10-13,15]}$ Decreasing the aging temperature to $763 \mathrm{~K}\left(490{ }^{\circ} \mathrm{C}\right)$ drastically 
reduced the kinetics of coarsening and $\kappa$-carbide observed in Figure 2 appears randomly distributed after 63 hours. This is consistent with the isothermal phase transformation diagram for a Fe-28Mn-8.5Al-1C-1.25Si alloy given by Acselrad and co-workers, which shows significant delay in $\kappa$-carbide growth and coarsening along cube directions at temperatures below $723 \mathrm{~K}\left(500^{\circ} \mathrm{C}\right) .{ }^{[14]} \mathrm{No}$ evidence of austenite decomposition or short-range ordering was observed in the as-quenched state; however, both satellite and superlattice reflections were observed to occur simultaneously from the earliest stages of aging observed during the current study as shown in Figure 2. Thus, it is impossible to determine if spinodal decomposition or short-range ordering occurred first.

The $\kappa$-carbide lattice parameters as determined from XRD for the 0.59 pct $\mathrm{Si}$ and 1.56 pct $\mathrm{Si}$ steels that were aged for 48 hours at $843 \mathrm{~K}\left(570^{\circ} \mathrm{C}\right)$ varied from 0.3718 to $0.3731 \mathrm{~nm}$ and these results are consistent with reported lattice parameters between 0.370 and $0.375 \mathrm{~nm}$ for $\kappa$-carbide precipitation below $973 \mathrm{~K}\left(700{ }^{\circ} \mathrm{C}\right)$ in a Fe-28Mn-8.5Al-1C-1.25Si alloy. ${ }^{[14]}$ Increasing both the silicon content as well as the aging temperature was shown to increase the lattice parameter of $\kappa$-carbide while simultaneously decreasing the austenite lattice parameter as silicon partitioned to the austenite. Increasing the amount of silicon from 0.59 to $1.56 \mathrm{pct}$ $\mathrm{Si}$ increased the constrained lattice misfit from 1.41 to 1.97 pet for alloys aged for 48 hours at $843 \mathrm{~K}\left(570{ }^{\circ} \mathrm{C}\right)$, as shown in Table II. Silicon partitioning to the austenite is in agreement with $a b$ initio calculations presented in this study as well as experimental findings by Huang et al. ${ }^{[46]}$

Silicon has also been shown to promote heterogeneous precipitation of $\mathrm{DO}_{3}$ and $\mathrm{B}_{2}$ intermetallic phases. ${ }^{[14]}$ However, the presence of these $\mathrm{D}_{3}$ or $\mathrm{B}_{2}$ iron aluminide phases was not detected by TEM or XRD in either of the silicon containing specimens, even after extended aging for 48 hours at $843 \mathrm{~K}\left(570^{\circ} \mathrm{C}\right)$, as shown in Figure 4. This is in contrast to the findings of Liu and co-workers, which report addition of 1.5 pct $\mathrm{Si}$ to a Fe-29Mn-8Al$0.9 \mathrm{C}$ alloy enhanced the formation of $\mathrm{D}_{3}$ in as-quenched samples. ${ }^{\text {[4] }}$

APT determined that silicon content had no effect on the total volume fraction of $\kappa$-carbide. The volume fraction of $\kappa$-carbide was determined between 0.18 and 0.19 after aging for 60 hours at $803 \mathrm{~K}\left(530^{\circ} \mathrm{C}\right)$ regardless of the amount of silicon. XRD profiles also show no significant variation in the volume fraction of $\kappa$-carbide with increasing silicon content (Figure 4). The values of the volume fractions of $\kappa$-carbide from the current study can be compared with 20 pct by volume as determined by XRD as per the results of Kalashnikov et al. ${ }^{[9]}$ for a Fe-28Mn-8.5Al-1C-1.25Si alloy that was aged 16 hours at $823 \mathrm{~K}\left(550{ }^{\circ} \mathrm{C}\right)$. Thus, the increased hardness with silicon addition cannot be attributed to an increase in the size or volume fraction of $\kappa$-carbide nor can it be attributed to the formation of intermetallic phases like $\mathrm{D}_{3}$. Alternatively, silicon may increase the strength and hardness by increasing the coherency strain between the $\kappa$-carbide and the austenite matrix.

It has been suggested that partitioning of manganese into the $\kappa$-carbide may increase the strength of $\kappa$-carbide by increasing the amount of $\mathrm{Mn}-\mathrm{C}$ bonds over weaker $\mathrm{Fe}-\mathrm{C}$ bonds and manganese-rich $\kappa$-carbides were reported in an atom probe study of a Fe-1.2C-3.2Mn-10Al (in at. pct) steel. ${ }^{[29]}$ In addition, Acelrad et al. ${ }^{[8]}$ reported that the addition of silicon produces a partitioning of manganese from the austenite matrix into grain boundary $\kappa$-carbide during aging and a study by Ishida et al. ${ }^{[48]}$ found evidence of homogeneously nucleated $\kappa$-carbide with a manganese composition 2 to 5 pct greater than the austenite matrix. However, in the current study, the manganese distribution across the interface of the matrix austenite and the $\kappa$-carbide shows that the $\kappa$-carbide is depleted of $\mathrm{Mn}$ as shown in Figures 8(a) and (d) and the partitioning coefficient for manganese was determined to be 0.9 , meaning slight partitioning of manganese to the austenite matrix. In their study of a mostly ferritic alloy, it was suggested by Seol et al. ${ }^{[29]}$ that the neighboring phase controls the partitioning of manganese and aluminum in $\kappa$-carbide. The study by Ishida confirms this to a degree and although they show slight partitioning of manganese into the homogeneous $\kappa$-carbide of austenitic alloys, they show significant partitioning of manganese, up to 15 pct greater, when the neighboring phase to the $\kappa$-carbide is ferrite. ${ }^{[4]}$ While it is possible that an increase in the number of $\mathrm{Mn}-\mathrm{C}$ bonds may increase the strength of $\kappa$-carbide, silicon was found to have little effect on the manganese distribution and thus manganese partitioning is not responsible for the increase in hardness with increasing silicon addition for the study presented here.

The most significant effect of silicon on the composition of $\kappa$-carbide is that silicon was shown to increase the partitioning of carbon into the $\kappa$-carbide during aging. Increasing the amount of silicon increased the amount of carbon in the $\kappa$-carbide from 5.32 to 6.55 at. pct, as shown in Table III. This is consistent with a $\kappa$-carbide composition of $(\mathrm{Fe}, \mathrm{Mn})_{3} \mathrm{AlC}_{x=0.3}$. In comparison, the composition of the lamellar $\kappa$-carbide in a study by Seol et al. ${ }^{[29]}$ of a mostly ferritic alloy was found to be $(\mathrm{Fe}, \mathrm{Mn})_{3}(\mathrm{Fe}, \mathrm{Al}) \mathrm{C}_{x=0.7}$ as measured by APT. Utilizing $\mathrm{X}$-ray diffraction and an empirical relationship for the amplitude of spinodal decomposition, Sato et al. ${ }^{[6]}$ calculated a $\kappa$-carbide composition of $(\mathrm{Fe}, \mathrm{Mn})_{3} \mathrm{AlC}_{x=0.4}$ for a Fe-30Mn-9A1-0.9C-0.03Si (0.016 pet P) alloy that was aged for 16 hours at $823 \mathrm{~K}\left(550^{\circ} \mathrm{C}\right)$. It should be noted that the stoichiometric $\kappa$-carbide has never been experimentally observed and has only been theoretically addressed using first-principles modeling.

As the amount of silicon was increased from 0.59 pct $\mathrm{Si}$ to 1.56 pct $\mathrm{Si}$, the partitioning coefficient of carbon increased from 2.1 to 2.9 as shown in Table IV. These results are consistent with the work of Acselrad et al. ${ }^{[14]}$ and Bannykh ${ }^{[49]}$ who showed that silicon accelerates carbide precipitation from austenite and raises the activity of $\mathrm{C}$ in the austenite solid solution. It was additionally reported that $\mathrm{C}$ and $\mathrm{Si}$ have similar levels of positive charge relative to iron ions and that they mutually repel each other, which is in agreement with $a b$ initio models in the current study. ${ }^{[4]}$ During aging, increasing the amount of carbon, and to a lesser extent aluminum, in $\kappa$-carbide contributes to a continuous increase in the lattice parameter with a simultaneous 
Table VIII. Mechanical Properties of the 1.07 and 1.56 pet Si Alloys as Obtained by Bartlett et al. ${ }^{[5]}$

\begin{tabular}{llcccc}
\hline Weight Percent Si & \multicolumn{1}{c}{ Heat Treatment } & Hdns $(\mathrm{BHN}) *$ & 0.2 pct YS (MPa) & UTS (MPa) & Percentage Elong.** \\
\hline 1.07 & Solution treated & 197 & 452 & 737 & 64 \\
1.56 & Solution treated & 208 & 450 & 733 & 64 \\
1.07 & Aged 60 h at $803 \mathrm{~K}\left(530^{\circ} \mathrm{C}\right)$ & $350 \pm 3$ & $873 \pm 17$ & $953 \pm 25$ & $20.1 \pm 10.1$ \\
1.56 & Aged 60 h at $803 \mathrm{~K}\left(530^{\circ} \mathrm{C}\right)$ & $360 \pm 6$ & $937 \pm 8.9$ & $1016 \pm 2.5$ & $13.2 \pm 4.2$ \\
\hline
\end{tabular}

*Hardness Brinell (3000 kg) was converted from Rockwell B and C scale measurements.

**Percentage elongation was measured in a $25.4 \mathrm{~mm}$ ( 1 in.) gage length.

Uncertainty reported for test sample greater than 2 and represents one standard deviation.

decrease in the austenite lattice parameter and this produces a greater strain at the interface of the $\kappa$-carbide with the matrix. ${ }^{[6,15]}$ Increasing the amount of silicon in the matrix would further decrease the austenite lattice parameter during aging and contribute to a greater misfit between the $\kappa$-carbide and the matrix. Sato et $a l .^{[6,15]}$ showed that the increase in strength and hardness in Fe-Mn-Al-C alloys during aging is related to the increase in the amplitude of the carbon concentration which increases the strain amplitude as a function of time.

Figure 1 shows an increase in hardness for a fixed aging time as the silicon is increased and this increased hardness may be explained by the change in carbon amplitude during spinodal decomposition. A theory of spinodal hardening presented by Kato et al. ${ }^{[50]}$ considered the increase in strength during aging to be the result of coherency stress associated with the growth in the composition amplitude. Thus, it is proposed that the increase in the carbon content of $\kappa$-carbide with increasing silicon content is responsible for the higher hardness at a fixed aging time. The extent of hardening with increasing silicon in the current study may be evaluated using the concentration amplitude of carbon determined from the atom probe analysis according to the model by Kato et al. given below ${ }^{[50]}$

$$
\begin{gathered}
\tau_{Y}=\frac{\varepsilon}{6^{\frac{1}{2}}}\left(C_{11}-C_{12}\right), \\
\varepsilon=\frac{A \eta\left(C_{11}+2 C_{12}\right)}{3 C_{11}},
\end{gathered}
$$

where $\Delta \tau_{\mathrm{y}}$ is the increase in the shear stress, $\varepsilon$ is the strain amplitude, and $A$ is the concentration amplitude of carbon which was measured to be 5.32 at. pet and 6.55 at. pet for the 0.59 and 1.56 pct $\mathrm{Si}$ specimens that were aged for 60 hours at $803 \mathrm{~K}\left(530{ }^{\circ} \mathrm{C}\right) . C_{11}$ and $C_{12}$ are elastic coefficients of the matrix and were taken to be $14.4 \times 10^{10}$ and $8.7 \times 10^{10} \mathrm{~N} / \mathrm{m}^{2}$ which were used by Sato et al. ${ }^{[6]}$ to accurately model increases in the yield strength during aging of a Fe-29.5Mn-9.2Al-0.94C steel. It should be noted however that these values were taken from the work of Salama and Alers and were determined for a single crystal of $\mathrm{Fe}-30 \mathrm{Ni} .{ }^{[51]}$ The parameter $\eta$ is the change in the lattice parameter as a function of increasing carbon concentration and $\eta=\mathrm{d} a / \mathrm{d} C \cdot 1 / a$. The change in the lattice parameter with increasing carbon content was determined by Sato et al. ${ }^{[6]}$ to be
0.18 using the data of Charles et al. ${ }^{[52]}$ for a similar Fe30Mn-9Al-0.9C-0.03Si (0.016 pet P) alloy. As a comparison, a $\eta$ value for the change in the $\kappa$-carbide lattice parameter with increasing carbon content was predicted to be 0.2 by extrapolating the data in Table II. This is very close to the value of 0.18 used in the Sato ${ }^{[6]}$ study. Multiplying $\Delta \tau_{\mathrm{y}}$ by an appropriate Taylor factor of 3.06 gives the change in the yield strength due to spinodal hardening. The increase in yield strength after aging for 60 hours at $803 \mathrm{~K}\left(530{ }^{\circ} \mathrm{C}\right)$ was predicted to be 500 and $620 \mathrm{MPa}$ for the 0.59 and 1.56 pct $\mathrm{Si}$ alloys, respectively. These calculated values can be directly compared with the tensile properties in Table VIII obtained by Bartlett et al. ${ }^{[5]}$ for the same 1.07 and 1.56 pct $\mathrm{Si}$ composition alloys used in the current study. Table VIII shows that after 60 hours of aging at $803 \mathrm{~K}\left(530^{\circ} \mathrm{C}\right)$, the yield strength increases by almost $500 \mathrm{MPa}$ in the 1.56 pct $\mathrm{Si}$ alloy which can be compared with a $620 \mathrm{MPa}$ increase in the yield strength as predicted by the hardening model by Kato et al. ${ }^{[0]}$

In the solution treated condition, the mechanical properties are nearly identical regardless of silicon content. However, in the 60 hours aged condition, increasing the silicon content by $0.5 \mathrm{wt}$ pct increased the yield strength by $64 \mathrm{MPa}$. The spinodal hardening model by Kato ${ }^{[49]}$ predicts a $120 \mathrm{MPa}$ increase in the yield strength with a $1 \mathrm{wt}$ pct increase in silicon for specimens aged for 60 hours at $803 \mathrm{~K}\left(530{ }^{\circ} \mathrm{C}\right)$. Within experimental error, the spinodal hardening mechanism is in reasonable agreement with the experimental results presented here as well as those presented by Sato et al. ${ }^{[15]}$

\section{SUMMARY}

For specimens aged for 60 hours at $803 \mathrm{~K}\left(530^{\circ} \mathrm{C}\right)$, it was determined that silicon accelerates the kinetics of $\kappa$-carbide formation, and therefore the precipitate size at a given aging time, but not the equilibrium volume fraction precipitated. Silicon was found to have little effect on the distribution of manganese and the $\kappa$-carbide was depleted of manganese regardless of silicon content; thus, the increase in hardening was not associated with changes in manganese content. Both experimental results and $a b$ initio calculations show that there is a repulsive interaction between carbon and silicon and carbon prefers to be far away from silicon in solution. Silicon was found to partition to the austenite during aging and silicon increased the activity of carbon 
in austenite. Increasing the silicon content from 0.59 to $1.56 \mathrm{wt}$ pct was found to increase the partitioning of carbon in the $\kappa$-carbide from 5.2 to 6.6 at. pct. The results of this study suggest that the increase in strength during aging of high manganese and aluminum steels is directly related to the increase in the compositional amplitude of carbon with silicon addition. A theory of spinodal hardening was used to calculate the expected increase in strength during aging with increases in the carbon concentration amplitude. The model predicted a $120 \mathrm{MPa}$ increase in strength with a $1 \mathrm{wt}$ pct increase in silicon for alloys aged for 60 hours at $803 \mathrm{~K}\left(530^{\circ} \mathrm{C}\right)$ and this is in reasonable agreement with previously determined mechanical property data.

\section{ACKNOWLEDGMENTS}

This work was supported in part by the Army Research Laboratory under contracts from Battelle Memorial Institute (contract W911NF-07-D-0001) and Benet Laboratories (contract W15QKN-07-2-0004) and by the National Science Foundation's MRSEC program (DMR-0520513) and made use of its Shared Facilities at the Materials Research Center of Northwestern University. Laura Bartlett was also supported by a U.S. Department of Education GAANN fellowship under contract P200A0900048. The FEI Tecnai F20 scanning/transmission electron microscope was obtained with a Major Research Instrumentation grant from NSF under contract DMR-0922851. The authors also gratefully acknowledge Waukesha Foundry, Inc. for providing the low phosphorous Fe-Mn-Al-C alloys and the alloys with varying $\mathrm{Si}$ contents. The local-electrode atom-probe tomograph at the Northwestern University Center for Atom-Probe Tomography (NUCAPT) was purchased and upgraded with funding from NSF-MRI (DMR-0420532) and ONRDURIP (N00014-0400798, N00014-0610539, N00014-09 10781) grants. Additional instrumentation at NUCAPT was supported by the Initiative for Sustainability and Energy at Northwestern (ISEN).

\section{REFERENCES}

1. R.A. Howell, S.L. Lekakh, D.C. Van Aken, and V.L. Richards: AFS Trans., 2008, vol. 116, pp. 867-78.

2. G. Frommeyer and U. Brux: Steel Res. Int., 2006, vol. 77, pp. 62733.

3. R. Howell, T. Weerasooriya, and D. Van Aken: AFS Trans., 2009, vol. 117 , pp. $751-63$.

4. G.L. Kayak: Metal Sci. Heat Treat., 1969, vol. 11, pp. 95-97.

5. L. Bartlett, R.A. Howell, A. Schulte, D. Van Aken, and K. Peaslee: MS\&T Conference Proceedings, Houston, TX, 2010.

6. K. Sato, K. Tagawa, and Y. Inoue: Metall. Trans. A, 1990, vol. $21 \mathrm{~A}$, pp. $5-11$.

7. G.E. Hale, A.J. Baker: Conference on Alt. Alloying for Environmental Research, New Orleans, LA, 1986.

8. O. Acselrad, I.S. Kalashnikov, E.M. Silva, R.A. Simao, C.A. Achete, and L. Pereira: Metall. Mater. Trans. A, 2002, vol. 33A, pp. 3569-72.
9. I.S. Kalashnikov, O. Acselrad, A. Shalkevich, L.D. Chumakova, and L.C. Pereira: J. Mater. Process. Technol., 2003, vol. 136, pp. $72-79$.

10. K. Sato, Y. Igarashi, Y. Inoue, T. Yamazaki, and M. Yamanaka: International Conference Stainless Steels, 1991, pp. 503-09.

11. W.K. Choo and J.H. Kim: Conference on Thermo-mechanical Processing of Steels and Other Materials, 1997, pp. 1631-37.

12. K.H Han, J.C. Yoon, and W.K. Choo: Scripta Mater., 1986, vol. 20 , pp. 33-36.

13. O. Acselrad, L.C. Pereira, and M.R. Amaral: Proceedings of Proc. and Prop. of Materials, 1992, pp. 829-34.

14. O. Acselrad, I.S. Kalashnikov, E.M. Silva, M.S. Khadyev, and R.A. Simao: Metal Sci. Heat Treat., 2006, vol. 48, pp. 543-53.

15. K. Sato, K. Tagawa, and Y. Inoue: Mater. Sci. Eng. A, 1989, vol. 111, pp. 45-50.

16. L. Bartlett, R. Howell, D. Van Aken, and K. Peaslee: AFS Trans., 2010, vol. 118, pp. 413-23.

17. C.Y. Chao and T.F. Liu: Scripta Metall., 1991, vol. 25, pp. 162328.

18. C. Hwang, C. Chao, and T. Liu: Scripta Metall. Mater., 1993, vol. 28 , pp. $263-68$.

19. C. Chao, C. Hwang, and T. Liu: Scripta Metall. Mater., 1993, vol. 28, pp. 109-14.

20. D. Isheim, R. Prakash, M. Fine, and D. Seidman: Scripta Metall., 2006, vol. 55, pp. 35-40.

21. M. Miller: Atom Probe Tomography: Analysis at the Atomic Scale, Kluwer Academic, New York, NY, 2000.

22. B. Gault, M. Moody, J. Cairney, and S. Ringer: Atom-Probe Microscopy, Springer Science and Business Media, New York, 2012.

23. T. Kelly and M. Miller: Rev. Sci. Instrum., 2007, vol. 78, pp. 1-20.

24. A. Murthy, J. Medvedeva, D. Isheim, S. Lekakh, V. Richards, and D. Van Aken: Scripta Mater., 2012, vol. 66, pp. 943-46.

25. K. Knipling, R. Karnesky, C. Lee, D. Dunand, and D. Seidman: Acta Mater., 2010, vol. 58, pp. 5184-95.

26. L. Johnson, M. Thuvander, K. Stiller, M. Oden, and L. Hultman: Thin Solid Films, 2012, vol. 520, pp. 4362-68.

27. W. Xiong, J. Agren, and J. Zhou: Condens. Matter Phys. Mater. Sci., May 2012.

28. D. Saxey, M. Apperley, R. Zheng, T. Honma, and S.P. Ringer: Mater. Forum, 2006, vol. 30, pp. 85-89.

29. J. Seol, D. Raabe, P. Choi, H. Park, J. Kwak, and C. Park: Scripta Mater., 2013, vol. 68 (6), pp. 348-53.

30. O.C. Hellman, J.A. Vanderbroucke, J. RuanSing, D. Isheim, and D.N. Seidman: Microsc. Microanal., 2000, vol. 6, pp. 437-44.

31. M. Miller and R. Forbes: Mater. Charact., 2009, vol. 60, pp. 46169.

32. G. Kresse and J. Hafner: J. Phys. Condens. Matter, 1994, vol. 6, pp. $8245-57$.

33. G. Kresse and J. Furthmuller: Phys. Rev. B, 1996, vol. 54, pp. 11169-186.

34. J.P. Perdew, K. Burke, and M. Ernzerhof: Phys. Rev. Lett., 1996, vol. 77 , pp. $3865-68$.

35. H.C. Herper, T. Hoffmann, and P. Entel: Phys. Rev. B, 1999, vol. 60 , pp. $3839-48$.

36. H.M. Lee: Metall. Trans. A, 1974, vol. 5A, pp. 787-79.

37. P. Willars, A. Prince, and H. Okamoto: Handbook of Ternary Alloy Phase Diagrams, vol. 3, ASM International, Materials Park, $\mathrm{OH}, 1995$.

38. M. Ruda, D. Farkas, and J. Abriata: Scripta. Mater., 2002, vol. 46, pp. 345-49.

39. P. Maugis, J. Lacase, R. Besson, and J. Morillo: Metall. Mater. Trans. A, 2006, vol. 37A, pp. 3397-401.

40. A. Kellou, T. Grosdidier, J. Raulot, and H. Aourag: Phys. Status Solidi B, 2008, vol. 245 , pp. $750-75$.

41. B.V. Reddy and S.C. Deevi: Mater. Sci. Eng. A, 2002, vols. 329331, pp. 395-401.

42. M. Palm and G. Inden: Intermetallics, 1995, vol. 3, pp. 443-54.

43. J. Yang, P. Laa, W. Liu, and Y. Hao: Mater. Sci. Eng. A, 2004, vol. 382 , pp. $8-14$.

44. H. Ishii, S. Miura, and T. Mohri: MRS Proceedings, 2002, vol. 753 p. BB5.29.

45. K.H. Han, W.K. Choo, D.Y. Choi, and S.P. Hong: Age Hardening in $\mathrm{Fe}-\mathrm{Mn}$-Al-C. Austenitic Alloys, TMS-AIME, Warrendale, PA, 1987, pp. 91-106. 
46. H. Huang, D. Gan, and W. Kao: Scripta Metall. Mater., 1994, vol. 30, pp. 499-504

47. T. Liu, J. Chou, and C. Wu: Metall. Trans. A, 1990, vol. 21A, pp. 1891-99.

48. K. Ishida, H. Ohtani, S. Naoya, R. Kainuma, and T. Nishizawa: ISIJ, 1990, vol. 30, pp. 680-86.
49. O. Bannykh: Fiz. Metal Metalloved., 1969, vol. 27, pp. 837-41

50. M. Kato, T. Mori, and L. Schwartz: Acta Metall., 1980, vol. 28, pp. 285-90.

51. K. Salama and G. Alers: J. Appl. Phys., 1968, vol. 39, pp. 4857-59.

52. J. Charles, A. Berghezan, and A. Lutts, J. Phys. Colloq., 1984, vol. 45, pp. C1-619-C1-623. 